\title{
Parametric Hull Form Optimization of Containerships for Minimum Resistance in Calm Water and in Waves
}

\author{
Yanxin Feng ${ }^{1} \cdot$ Ould el Moctar $^{1} \cdot$ Thomas E. Schellin $^{1}$
}

Received: 29 June 2021 / Accepted: 27 September 2021 / Published online: 17 January 2022

(c) The Author(s) 2022

\begin{abstract}
This paper described the process of generating the optimal parametric hull shape with a fully parametric modeling method for three containerships of different sizes. The newly created parametric ship hull was applied to another ship with a similar shape, which greatly saved time cost. A process of selecting design variables was developed, and during this process, the influence of these variables on calm water resistance was analyzed. After we obtained the optimal hulls, the wave added resistance and motions of original hulls and optimal hulls in regular head waves were analyzed and compared with experimental results. Computations of the flow around the hulls were obtained from a validated nonlinear potential flow boundary element method. Using the multi-objective optimization algorithm, surrogate-based global optimization (SBGO) reduced the computational effort. Compared with the original hull, wave resistance of the optimal hulls was significantly reduced for the two larger ships at Froude numbers corresponding to their design speeds. Optimizing the hull of the containerships slightly reduced their wave added resistance and total resistance in regular head waves, while optimization of their hulls hardly affected wave-induced motions.
\end{abstract}

Keywords Parametric hull $\cdot$ Optimization $\cdot$ Wave added resistance $\cdot$ DAKOTA $\cdot$ Surrogate-based global optimization

\section{Introduction}

The International Maritime Organization (IMO) requires that all new ships meet minimum energy efficiency levels according to the Energy Efficiency Design Index (EEDI). This requirement can be satisfied by reducing emissions, a measure that also decreases fuel costs. To reach this goal, optimizing a ship's hull for least resistance became a relevant design issue because hull shape significantly affects ship performance. Successful optimization involves

\section{Article Highlights}

- Parametric hulls are generated for different containerships to realize automatic optimization process for vessels.

- The resistances of subject vessels in calm water and head waves are predicted using GL Rankine code.

- An effective optimization algorithm SBGO is applied to obtain the optimized vessels.

Yanxin Feng

yanxin.feng@uni-due.de

1 Institute of Ship Technology, Ocean Engineering and Transport Systems (ISMT), University of DuisburgEssen, 47057 Duisburg, Germany geometric variation of the hull form. Combined with computational fluid dynamics (CFD) methods, we applied a computer-aided design (CAD) method to parametrically model and subsequently optimize the hull shape of three generic containerships.

Parametric modeling techniques in CAD can be subdivided into three phases, namely, wireframe modeling, surface modeling, and solid modeling. Of these, a fully parametric modeling method portrays the entire hull, whereas a partially parametric model describes only the changed part of an existing hull. Tin and Tun (2016), for example, employed a partially parametric model to optimize the bulbous bow of a containership. The fully parametric modeling method is the preferred approach to improve the efficiency at the early stages of ship design. Nowacki (1977) used the fully parametric design method to optimize hull curves by means of cubic B-splines with vertices obtained from form parameters. Kracht (1978) presented a set of form coefficients to characterize a bulbous bow and concluded that the volumetric parameter has the largest influence on resistance. Employing hull parametric modeling, Kracht and Jacobsen (1992) defined certain parameters to control the hull form of a new model series, the so-called D Series, originating 
from a twin-screw round bilged ship. Harries and Abt (1998) selected 13 parameters representing positional, integral, and differential shape requirements to generate a flexible geometry that adopted these shape requirements. Harries (1998) developed a special technique to simplify the generation of the parametric hull form via surface curves using form parameters that control the hull from. This parametric approach was fully based on uniform B-spline curves, and form parameters defined the hull surfaces via a variation formula. Brizzolara et al. (2015) compared two parametric approaches, namely, the free-form deformation (FFD) approach and the full parametric approach (FPA). They found out that the FPA approach is better able to provide feasible and realistic hull forms, both in terms of stability of the optimization procedure and design viability of the attained optimum shape. Therefore, we applied also the FPA approach to generate parametric models.

Automatic optimization procedures are computationally demanding. A surrogate-based optimization can be used to reduce the computational burden. Queipo et al. (2005) presented an overview of surrogate-based optimizations. They compared several approaches in design space sampling, surrogate model construction, model selection and validation, sensitivity analysis, and surrogate-based optimization. The surrogate acceleration technique has been widely used in ship design and optimization. Scholcz et al. (2015) used surrogates to obtain approximate Pareto fonts for a chemical tanker. They found that the ship design process can be accelerated, leading to more efficient ships. Rotteveel et al. (2016) studied the effect of numerous hull forms and conditional variations. They applied surrogate models for different water depths for the final design trade-offs. Scholcz and Veldhuis (2017) reduced the computer time from two weeks to only one day by using the surrogate-based global optimization (SBGO) technique instead of a multi-objective genetic algorithm (MOGA). They demonstrated that the SBGO technique is a promising approach to mitigate the computational burden for multi-dimensional design spaces or multi-level optimization problems that arise naturally in naval ship designs.

Our aim was to apply an automatic optimization process on three different sized of containerships, namely, the Duisburg Test Case (DTC), the Kriso containership (KCS), and the S-175 containership. For the DTC, El Moctar et al. (2012) provided experimental results based on model tests for benchmarking. Previous research of El Moctar et al. (2017) numerically investigated wave added resistance for this ship and for a cruise ship using the two Reynoldsaveraged Navier-Stokes (RANS) solvers, OpenFOAM and COMET. They applied an implicit solver to compute nonlinear six degrees-of-freedom ship motions and obtained comparable results that agreed fairly well with model test measurements. Riesner and El Moctar (2018) developed a nonlinear time-domain Rankine source method to calculate the wave-induced added resistance of the DTC and a large tanker at constant forward speed in regular head waves. Riesner et al. (2018) computed speed loss, engine output, and fuel consumption for this DTC, for the KVLCC2 tanker, and for a cruise ship.

For the KCS, research involved model testing at the Korean Research Institute of Ships and Ocean Engineering (Van 1997; Van 1998a, b) and at the Ship Research Institute of Japan (Kume 2000). Larsson et al. (2003) selected the KCS for one of their self-propulsion test cases to validate predicted mean velocities, surface pressures, wave profiles, and resistances for this ship under stern flow conditions with and without an operating propeller. Kim et al. (2001) provided a benchmark database using CFD techniques to validate ship hydrodynamic predictions, including global forces, wave patterns, and local mean velocity components around the KCS measured in a towing tank. Zhang (2010), computing the flow around the KCS on three computational grids, verified and validated resistance predictions and wave profiles based on ITTC (2002a) recommended procedures. Gaggero et al. (2015) used an OpenFOAM RANS solver to predict calm water resistance and propeller open water characteristics for the KCS. Chen et al. (2019) performed RANS simulations to calculate the resistance of a model of the KCS under similar conditions.

For the S-175, Fujii (1975) conducted numerous experimental investigations and numerical simulations to predict the wave added resistance and the corresponding motions in regular waves. Fonseca and Guedes Soares (2004), after carrying out experiments on a model of the S-175 at constant speed in regular head waves, demonstrated that the nonlinear behavior of the vertical responses is similar at Froude numbers between 0.15 and 0.25. Papanikolaou and Liu (2010) implemented a three-dimensional frequency domain panel code in their method to predict the wave added resistance of the S-175 in waves, and they showed that their method is reliable and robust for routine predictions of the wave added resistance of a ship in waves. Somayajula et al. (2014) developed a three-dimensional panel code based on Green functions to determine the S-175's wave-induced motions and wave added resistance using the near field pressure integration technique. Kim et al. (2017) applied a two-dimensional and a three-dimensional flow scheme and an unsteady Reynolds-averaged Navier-Stokes (URANS) approach to predict motions and wave added resistance of the S-175 in regular head and oblique waves.

Applying the fully parametric modeling technique of CAESES, we generated a parametric hull of the DTC, i.e., a hull of a containership with a bulbous bow. We used this process also for the hull of the smaller but similar KCS containership by changing only the parameters. For the smallest S-175 containership, which is a hull without a bulbous bow, 
we generated another parametric hull, and for this hull and its optimal hull, we carried out numerical simulations. For the two containerships DTC and KCS, we analyzed total resistance at various speeds under calm water conditions and compared results with experimental data. The wave added resistance of DTC at the Froude number of 0.139 and KCS at the Froude number of 0.26 in head waves was predicted and compared with experimental results. For S-175, we also predicted the added resistance at the Froude number of 0.250 in regular waves and compared the results with corresponding experimental data. The potential flow solver GL Rankine performed all our numerical simulations. This solver is a nonlinear free surface Rankine panel method. Heinrich et al. (2014) employed a new Rankine panel method and an extended RANS solver to predict wave added resistance in head waves at different Froude numbers of a Wigley hull, a large tanker, and a modern containership. They concluded that the potential flow method GL Rankine was appreciably faster than the RANS solver for the prediction of wave added resistance of ships in waves. Meanwhile, RANS-based simulations provided validation data for potential codes. With this validated potential code, as in our previous work, where we optimized the hull of a wind offshore supply vessel (Feng et al. 2020a), we combined GL Rankine with CAESES using two different genetic algorithms. Here in this study, to reduce the computational effort, we relied on the SBGO optimization algorithm implemented in the open source software DAKOTA (Adams et al. 2009). Similar process was developed in our previous work for DTC (Feng et al. 2020b). The parametric hull created for DTC is used here to check whether it is suitable to KCS, which has a similar ship hull as DTC. We compared results of our optimization process with experimental data from former researchers' work and analyzed the influence of optimal hulls on the resistances of these three containerships. The influence of the optimization process on different sizes of containerships is discussed and analyzed.

\section{The Subject Containerships}

We considered three differently sized containerships, here identified as DTC, KCS, and S-175. The DTC is a modern 14000TEU post-Panamax container carrier, the so-called Duisburg Test Case (DTC). Its hull was developed at the Institute of Ship Technology, Ocean Engineering and Transport Systems (ISMT). The KCS is the well-known 3600TEU KRISO containership test case. It was designed by the Maritime and Ocean Engineering Research Institute (MOERI) to provide data to examine flow physics and to validate CFD computations for a modern container ship with a bulbous bow and a bulbous stern. The S-175 is one of the benchmark hull forms used by researchers to study its seakeeping capability. Figure 1 shows the original hull forms of these vessels, and Table 1 lists their principal particulars. An IGES model of the DTC was available from ISMT (2012), and model data and test conditions of the KCS were documented by MOERI (2008).

\section{Parametric Modeling}

The new hull form, i.e., a three-dimensional parametric model was created from a set of parameters that relate hull dimensions and selected design constraints. By changing one of these parameters, the other parameters that depend on these parameters were automatically updated. The parts to be optimized were cut out or removed and finally replaced by a parametric geometry. We optimized the entire hull body of the subject containerships. Therefore, we replaced the imported IGES model files with a parametric model. We relied on fully parametric modeling to create a parametric model of the ships' hulls, which were defined by specific design requirements satisfied by generating or changing specific descriptors.

Obtaining a parametric model required three steps. First, basic curves had to be confirmed; second, curve engines had to be defined; third, meta surfaces had to be generated. Most curves of the parametric model were obtained using poly-curves with F-splines that allowed the user to control the entrance and the run angle of each curve and the area and centroid of some segments of the curve. To achieve this goal, some parameters were created for the entrance and run angles, and other parameters that represented an area coefficient for the segments were manipulated when needed.

The first step to generate an F-spline was to obtain input form parameters, such as start and end points, entrance locations, and run angles. We used a parameter named "fullness" to change different areas of curves. Figure 2 presents an example of an F-spline with three different area constraints. The fullness of curves $\mathrm{C} 1, \mathrm{C} 2$, and $\mathrm{C} 3$ was $1.0,0.5$, and 1.5 , respectively. We obtained the needed curves by changing the chosen design variables, such as entrance angle, run angle, and fullness. We divided the parametric design of the hull form into four phases, namely, specification of main particulars,

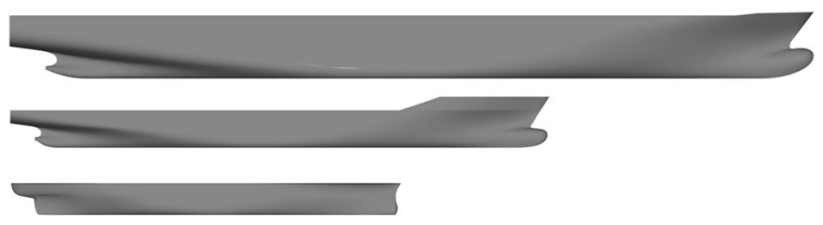

Figure 1 Original hull forms of the DTC (top), the KCS (center), and the S-175 (bottom) 
Table 1 Principal hull particulars of the DTC, the KCS, and the S175

\begin{tabular}{|c|c|c|c|c|c|c|}
\hline \multirow{2}{*}{$\begin{array}{l}\text { Containership } \\
\text { Designation }\end{array}$} & \multicolumn{2}{|l|}{ DTC } & \multicolumn{2}{|l|}{ KCS } & \multicolumn{2}{|l|}{ S-175 } \\
\hline & Full scale & Model scale & Full scale & Model scale & Full scale & Model scale \\
\hline Scale ratio & 1.0 & $1 / 59.407$ & 1.0 & $1 / 31.599$ & 1.0 & $1 / 40$ \\
\hline Length between perpendiculars (m) & 355.0 & 5.976 & 230.0 & 7.279 & 175.0 & 4.375 \\
\hline Depth (m) & 30.15 & 0.508 & 19.0 & 0.601 & 11.0 & 0.275 \\
\hline Breadth $(\mathrm{m})$ & 51.0 & 0.859 & 32.2 & 1.019 & 25.4 & 0.635 \\
\hline $\operatorname{Draft}(\mathrm{m})$ & 14.5 & 0.244 & 10.8 & 0.342 & 9.5 & 0.238 \\
\hline Displacement $\left(\mathrm{m}^{3}\right)$ & 173467.0 & 0.827 & 52030.0 & 1.649 & 23680 & 0.377 \\
\hline Block coefficient $\left(C_{B}\right)$ & 0.661 & 0.661 & 0.651 & 0.651 & 0.572 & 0.572 \\
\hline Wetted surface area $\left(\mathrm{m}^{2}\right)$ & 22032.0 & 6.243 & 9530.0 & 9.544 & 4927.6 & 3.080 \\
\hline Design speed (kn) & 25.0 & 3.244 & 24.0 & 4.269 & 21.9 & 3.188 \\
\hline
\end{tabular}

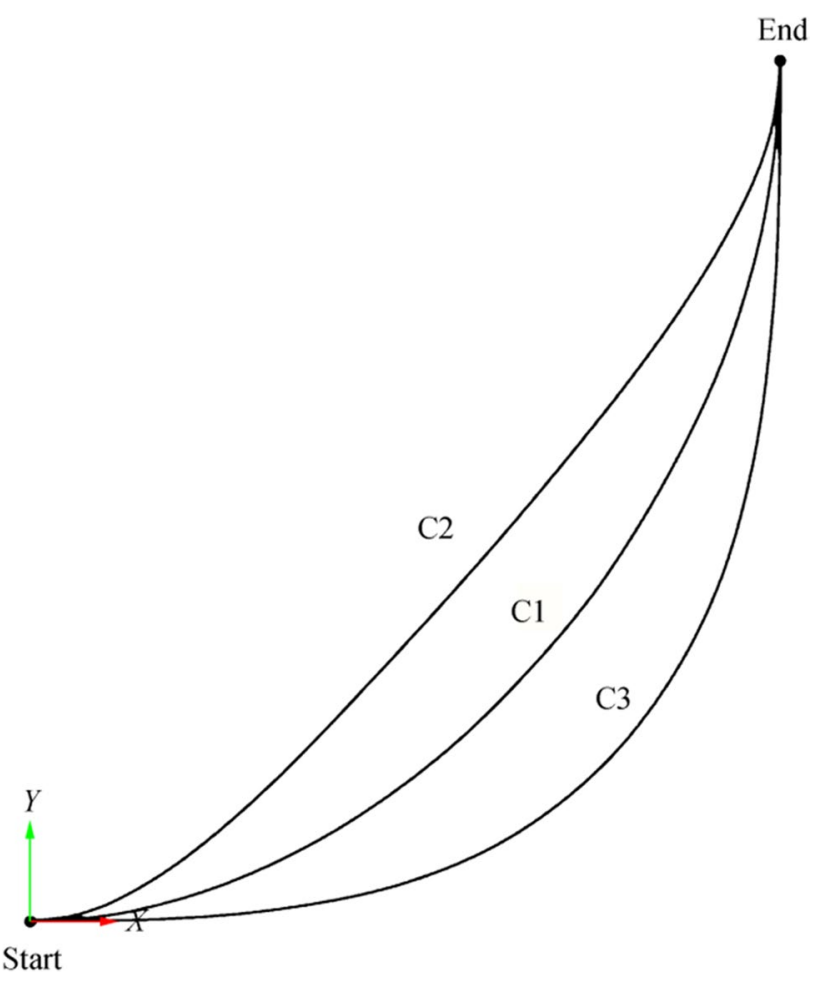

Figure 2 Fairness-optimized parametric curves with different area constraints

obtaining the basic parametric design curves, determining the parametric design section curves, and generating the hull form.

\subsection{Specifying the Hull's Main Particulars}

To satisfy specific requirements, we specified principal dimensions and coefficients, such as $L_{\mathrm{pp}}, B, T$, and $C_{B}$. The overall dimensions defined the frame of the ship hulls.

\subsection{Parametric Design of Basic Curves}

The model for the hull surface of each ship was primarily constructed of basic curves, which were determined by the parameters. Starting from the stem, these curves comprised bulbous bow curves, longitude curves, and diagonal curves.

1) A bulbous bow, if designed appropriately, reduces the ship's resistance, and, therefore, its shape is relevant for hull design. Curves to create the bulbous bow were grouped as follows: top elevation curves for the upper profile (TopElevation), keel elevation curves for the lower profile (KeelElevation), beam elevation curves for the height at maximum width (BeamElevation), and beam curves for the maximum width of the beam curves (MaxBeam). Longitudinal positions (Xpos) were specified for each of these curves, and fullness curves (FullnessCurves) and tangent curves (TangentCurves) defined entrance and run angles of each curve.

Both DTC and KCS have bulbous bows, while the S-175 does not. For the KCS, we used the pro-

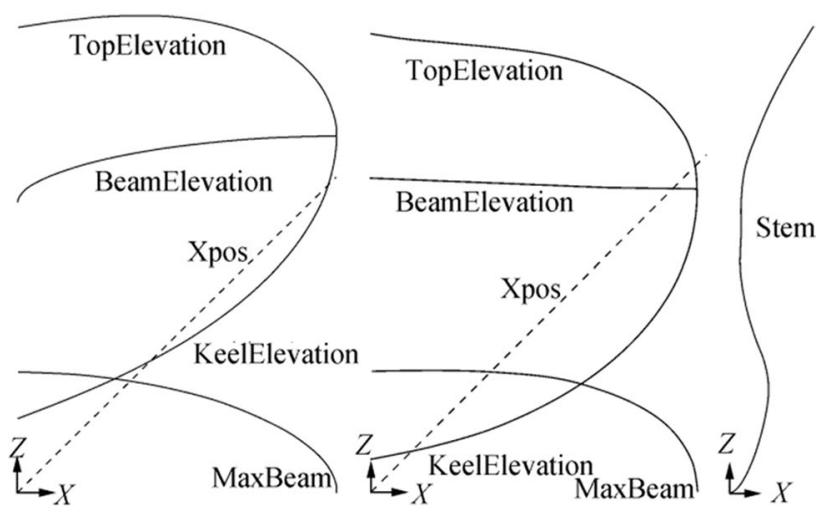

Figure 3 Profile curves of the bulbous bow of the DTC (left) and the KCS (center), and the stem profile of the S-175 (right) 
file curves of the DTC as we only had to change the parameters to fit the size of the KCS's hull. For the S-175, instead of creating curves for its bulbous bow, we used only one single curve to control the stem of its hull. The fullness of the stem curve determined the shape of the stem. Figure 3 presents the difference between profile curves of the bulbous bow for the DTC and the KCS as well as of the stem profile for the S-175. This figure shows perspective views to better identify these curves for each hull. All subsequent figures refer to these three hull forms, created by following the same procedure.

2) For the DTC and the KCS, the longitude curves that modeled the hull frame comprised deck curves (Deck), over deck curves (Overdeck), the design waterline (DWL), flat of side curves (FOS), flat of bottom curves (FOB), center plane curves (CPC), and transom curves (Transom). For the S-175, the longitude curves comprise only DECK, FOS, DWL, FOB, and $\mathrm{CPC}$ curves. Figure 4 shows longitude curves of each hull.

3) For the DTC and the KCS, three diagonal curves (diagonal 1, diagonal 2, and diagonal 3) controlled the shape of their stern. For the S-175, only one single stern curve was created to control the shape of its stern; see Figure 5.

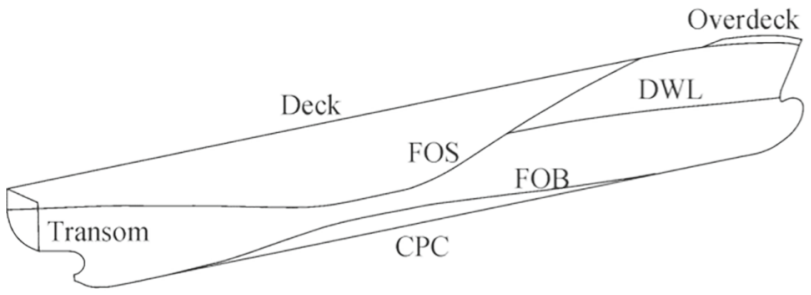

(a) Basic curves of DTC

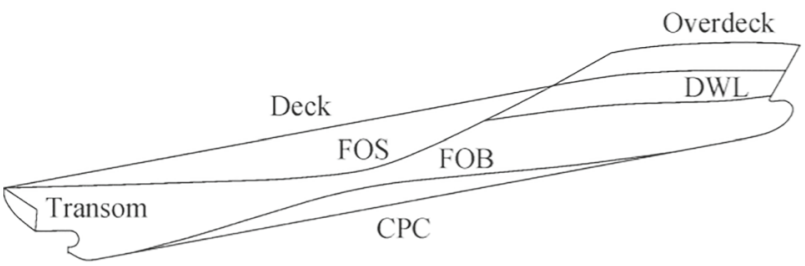

(b) Basic curve of KCS

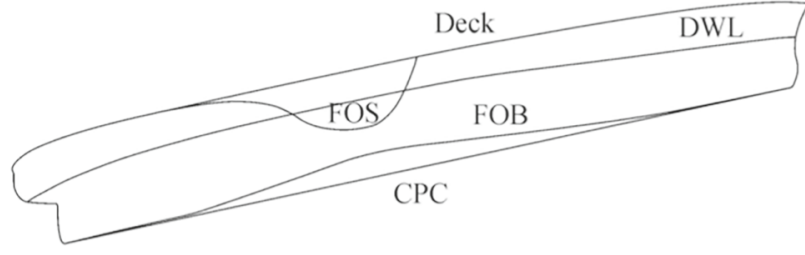

(c) Basic curve of S-175

Figure 4 Longitude curves of the hull for the DTC, the KCS, and the S-175

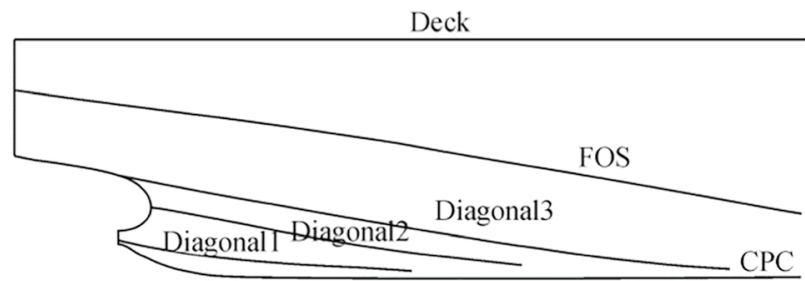

(a) Profile curves of the aft body for the DTC

Deck

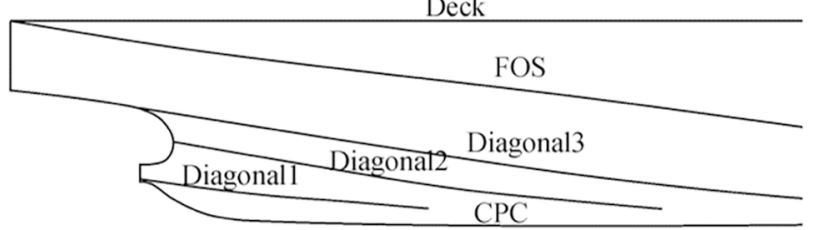

(b) Profile curves of the aft body of the KCS

Deck

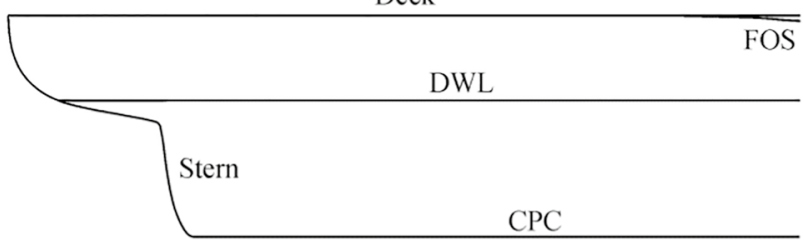

(c) Profile curves of the aft body of the S-175

Figure 5 Profile curves of the ships' aft body for the DTC, the KCS, and the S-175

\subsection{Parametric Design of Ship Sections}

To create meta surfaces with adequate accuracy for the parametric models, we defined additional cross sections extending from stem to stern as shown in Figure 6. As seen, only the DTC has a midbody, while the KCS and the S-175 do not. We created the parametric hull for the DTC, which has a midbody length of $24.4 \mathrm{~m}$. Therefore, when applying the parametric model to the KCS, the midbody had to be deleted. However, deleting the midbody directly would have destroyed their connections, but connections were necessary

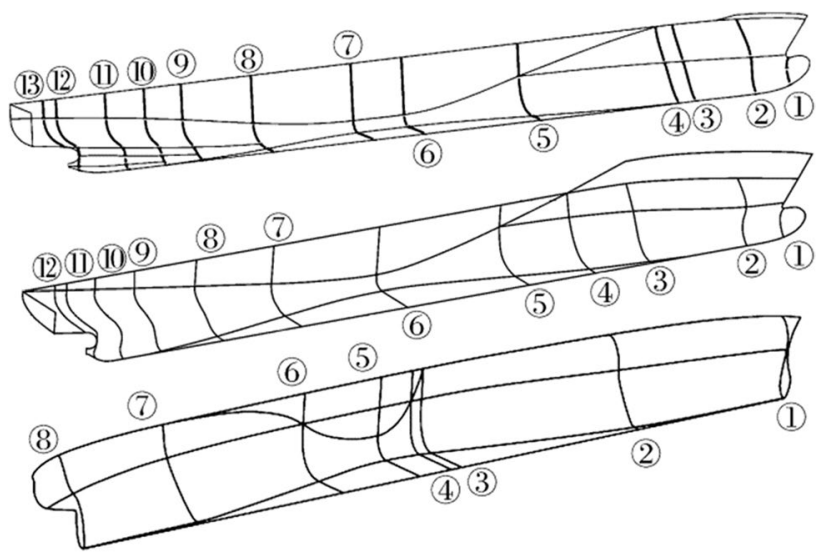

Figure 6 Ship section curves along the longitudinal direction for the DTC (top), the KCS (center), and the S-175 (bottom) 
Table 2 Definition of section positions of the DTC, the KCS, and the S-175

\begin{tabular}{|c|c|c|c|}
\hline $\mathrm{Nr}$. & DTC & KCS & S-175 \\
\hline 1 & Start of bulbous bow & Start of bulbous bow & Start of FOB \\
\hline 2 & Start of keel for bulbous bow & Start of FOB & Middle position between section 1 and 3 \\
\hline 3 & Start of FOB & Start of Overdeck & Start of FOS \\
\hline 4 & Start of FOS & Start of FOS & $\begin{array}{l}\text { Longitudinal position of crossing point } \\
\text { of DWL and FOS at forebody }\end{array}$ \\
\hline 5 & $\begin{array}{l}\text { Longitudinal position of crossing point } \\
\text { of DWL and FOS }\end{array}$ & $\begin{array}{l}\text { Longitudinal position of crossing point of } \\
\text { DWL and FOS }\end{array}$ & Longitudinal position of amidships \\
\hline 6 & Start of midbody & Longitudinal position of amidships & $\begin{array}{l}\text { Longitudinal position of crossing point } \\
\text { of DWL and FOS at aftbody }\end{array}$ \\
\hline 7 & End of midbody & Start of diagonal 3 & End of FOS \\
\hline 8 & Start of diagonal 3 & Start of diagonal 2 & End of FOB \\
\hline 9 & Start of diagonal 2 & Start of diagonal 1 & None \\
\hline 10 & Start of diagonal 1 & End of FOB & None \\
\hline 11 & End of FOB & End of diagonal 2 & None \\
\hline 12 & End of diagonal 2 & End of diagonal 3 & None \\
\hline 13 & End of diagonal 3 & None & None \\
\hline
\end{tabular}

to regenerate a new parametric hull. As creating new connections was time-consuming, we assumed the length of the midbody to be relatively small. Then the midbody was slim enough to be considered as a line. Here, for the KCS we assumed a length of $0.1 \mathrm{~m}$ for its midbody. The parametric hull of the DTC was not suitable for the S-175, because its shape was too different. For the S-175, we created a new parametric hull without a midbody and, instead, we constructed a midship line.

Figure 6 shows 13 section lines along the longitudinal direction of the DTC's hull and, due to its missing the midbody, one section line less on the KCS's hull. For the S-175, only eight sections sufficed to define the entire hull because diagonal curves were not required for its stern and its midbody. All longitudinal positions were individually specified. Table 2 lists the positions of these sections for the DTC, the KCS, and the S-175 as well as relevant details. The entry "None" in this table means that sections did not exist for the associated ship hull.

\subsection{Generation of Hull Forms}

A generated parametric hull consisted of so-called meta surfaces as seen in Figure 7. A meta surface is a parametric sweep surface subject to several user controls. Hence, it is a highly flexible surface, especially convenient for efficient shape optimization by means of a simulation tool. The following three steps were necessary to generate a meta surface:
1) Curve definition: the custom curve definition was based on feature definitions that specified, for example, the type of curve, their start and end points, and their entrance and run angles.

2) Curve engine setup: the curve engine connected the functional curves defined in step 1 .

3) Meta surface generation: meta surfaces were created within a specified interval using the curve engine of step 2 .

Figure 8 shows comparative body plans and side profiles of the parent hull and the parametric hull for the DTC, $\mathrm{KCS}$, and S-175. Blue lines mark bodylines of the original hulls; red lines, bodylines of the parametric hulls. As seen, for DTC and KCS, compared to the original bodylines,

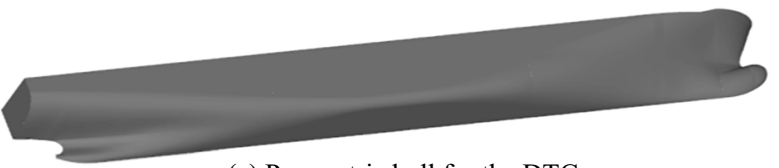

(a) Parametric hull for the DTC

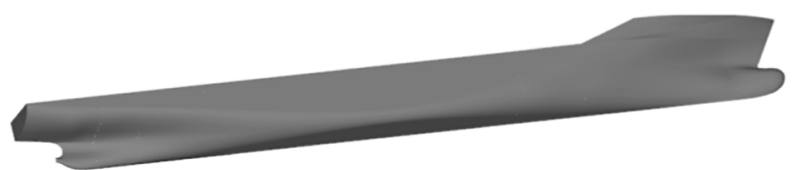

(b) Parametric hull for the KCS

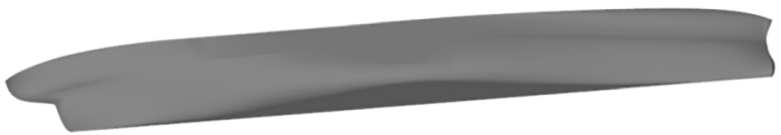

(c) Parametric hull for the S-175

Figure 7 Parametric hulls for the DTC, the KCS, and the S-175 


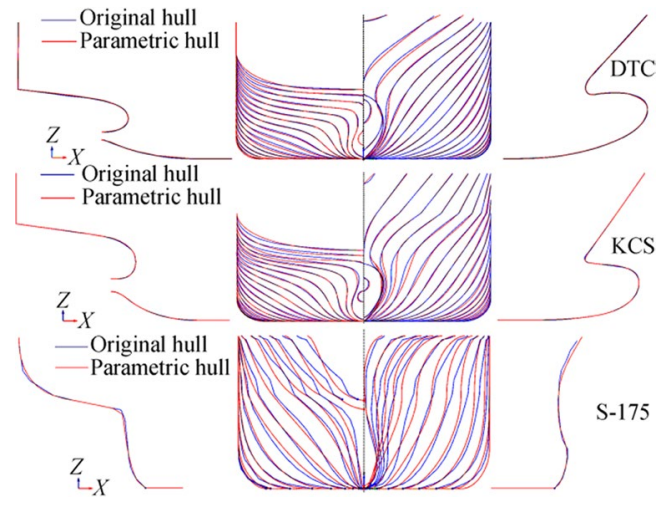

Figure 8 Comparative body plans and side profiles of the parent hull (blue) and the parametric hull (red) for the DTC, KCS, and S-175

the parametric bodylines differ only slightly. This demonstrated that it was possible to apply the parametric hull of DTC also to the similar hull of the KCS by changing the corresponding design variables. In the same way, this parametric hull can be applied to other containerships with a similar hull, which helped to reduce computational costs. For the S-175, these differences were comparatively greater than for the other two hulls. We started with offset values of the S-175 to specify the input information of the other hulls, which led to somewhat irregular bodylines of the original S-175 hull. The changed hull form and its optimization were then based on the parametric hull. However, the resulting slight difference was a measure for reliable results.

\section{Numerical Approach}

\subsection{Linear Reponses in Waves Using Rankine Sources}

The GL Rankine method we applied is a frequency domain method based on Rankine sources. Söding et al. (2012) developed this code to calculate frequency dependent hydrodynamic response coefficients and diffraction forces. This method accounts for the interaction between the nonlinear stationary flow in calm water (including steady ship waves and dynamic trim and sinkage) and the periodic flow in waves. In potential theory, the fluid is assumed to be ideal, i.e., incompressible and inviscid, and the flow is assumed irrotational. If the flow velocity is an irrotational vector field, a velocity potential exits. The total potential $\phi^{t}\left(\omega_{e}\right)$ in waves is assumed to be a superposition of the steady potential $-u x+\phi^{0}$ and the periodic potential of complex amplitude $\hat{\phi}^{1}$, which oscillates with encounter frequency $\omega_{e}$ : $\phi^{t}(\boldsymbol{x}, \boldsymbol{t})=u x+\phi^{0}(\underline{\boldsymbol{x}})+\operatorname{Re}\left(\hat{\phi}^{1} \mathrm{e}^{\mathrm{i} \omega_{e} t}\right)$

where $\boldsymbol{x}$ designates the same location as $\boldsymbol{x}$ expressed in a coordinate system fixed to the ship's hull. It is assumed that $\phi^{1}$ depends linearly on the wave amplitude.

The dynamic boundary condition is expressed as follows:

$$
\begin{gathered}
\nabla \phi^{0}-\boldsymbol{U}\left[\nabla \hat{\phi}^{1}+\boldsymbol{a} \times \nabla \phi^{0}-\left(\nabla^{2} \phi^{0}\right) \boldsymbol{v}\right] \\
+\mathrm{i} \omega_{e}\left(\hat{\phi}^{1}-\boldsymbol{v} \nabla \phi^{0}\right)+g\left(\hat{\zeta}^{1}-\boldsymbol{v} \nabla \zeta^{0}\right)=0
\end{gathered}
$$

where $\boldsymbol{U}=[u, 0,0]^{\mathrm{T}}$ denotes the ship velocity vector of the steady inflow, $\hat{a}$ the amplitude of the ship rotation vector, $\hat{v}$ the amplitude of the total motion of a point on the ship, $\mathrm{i}$ the imaginary unit number, and $\zeta^{0}=\zeta^{0}(\boldsymbol{x}, \boldsymbol{y})$ the free surface elevation. The superscript 0 is used for the steady solution. The kinematic boundary condition reads as follows:

$$
\begin{gathered}
\mathrm{i} \omega_{e}\left(\hat{\zeta^{1}}-\hat{\boldsymbol{v}} \nabla \zeta^{0}\right)+\nabla \zeta^{0} \nabla \hat{\phi}^{1}+\left(\nabla \phi^{0}-\boldsymbol{U}\right) \nabla \hat{\zeta}^{1} \\
+\frac{\partial}{\partial z} \hat{\phi}^{1}+\hat{\boldsymbol{a}}\left[-\frac{\partial \phi^{0}}{\partial y}, \frac{\partial \phi^{0}}{\partial x}, u \frac{\partial \zeta^{0}}{\partial y}\right]^{T}+\hat{A}=0
\end{gathered}
$$

where $\hat{A}$ includes all second order derivatives and is written as follows:

$\hat{A}=\frac{-\hat{\boldsymbol{v}} \boldsymbol{n}^{0}}{\left|\boldsymbol{n}^{0}\right|^{2}} \boldsymbol{n}^{0}\left[\left(\nabla^{2} \boldsymbol{\phi}^{0}\right) \boldsymbol{n}^{0}+\left(\nabla^{2} \zeta^{0}\right)\left(\nabla \phi^{0}-\boldsymbol{U}\right)\right]$

where $\boldsymbol{n}^{0}$ is the normal vector of the stationary free surface:

$\boldsymbol{n}^{0}=\left[\frac{\partial \zeta^{0}}{\partial x}, \frac{\partial \zeta^{0}}{\partial y},-1\right]^{\mathrm{T}}$

Relying on the approach of Hachmann (1991), terms involving second derivatives of the steady potential are transformed from the body boundary condition to the kinematic boundary condition on the free surface. Based on experience, this approach ensures more accurate results, particularly at large Froude numbers. Söding et al. (2012) described additional details about this frequency domain approach. The special feature of Hachmann's strip method is that the steady flow filed follows not only the average forward motion of the ship, but also participates in the periodic flow motion. This, together with the interaction between the steady potential $\phi^{0}$ and the periodic first-order potential

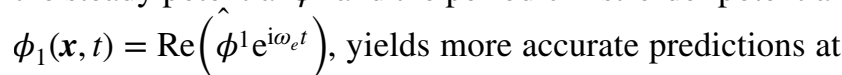
higher forward speeds.

In Eq. (1), the difference between vectors $\mathrm{x}$ in inertial coordinates and $\boldsymbol{x}$ in body-fixed coordinates is described by the following second-order equation:

$x=\underline{x}+v_{1}+v_{2}$ 
where $\boldsymbol{v}_{\mathbf{2}}=\boldsymbol{a} \times\left(\boldsymbol{a} \times \underline{x}-\underline{x}_{g}\right) / 2$ represents first-order terms, and $\boldsymbol{v}_{\mathbf{1}}=\boldsymbol{u}+\boldsymbol{a} \times\left(\underline{\boldsymbol{x}}-\underline{x}_{g}\right)$ represents second-order terms, respectively. Here, $\boldsymbol{u}$ denotes the displacement of the ship's center of gravity and a the rotation of the hull.

The second-order force is separated into two main contributions, namely, the pressure force $\mathrm{F}_{A}$ acting on the hull up to the average waterline (expressed in hull-bound coordinates) and the force $\mathrm{F}_{B}$ caused by the variation of hull submergence. Force $\boldsymbol{F}_{B}$ is the sum of three contributions:

$\boldsymbol{F}_{A}=\sum_{\text {panels }}(\underbrace{\underline{p}_{1} f_{1}}_{A}+\underbrace{p_{0} f_{2}}_{B}+\underbrace{p_{2} f_{0}}_{C})$

where indices 0,1 , and 2 designate the order of pressure $p$ in hull-fixed coordinates and of the area vectors fof the panels in inertial coordinates. Area vectors f are normal vectors on hull panels, pointing into the hull, with magnitudes equal to panel areas. They are defined as follows:

$f_{0}=\underline{f}, f_{1}=a \times f, f_{2}=a \times(a \times f) / 2$

Pressure of order 0,1 , and 2 are defined as follows:

$\hat{p}_{0} / \rho=-g z$

$p_{1} / \rho=\operatorname{Re}\left(\hat{p}_{1} \mathrm{e}^{-\mathrm{i} \omega_{e} t}\right) / \rho$

with

$$
\begin{gathered}
\hat{p}_{-1} / \rho=-\left(\nabla \phi^{0}-\boldsymbol{U}\right)\left(\nabla \hat{\phi}+\boldsymbol{a} \times \nabla \phi^{0}\right) \\
-\mathrm{i} \omega_{e}\left(\hat{\phi}-\hat{v}_{1} \nabla \phi^{\mathbf{0}}\right)-g \hat{v}_{1 z}
\end{gathered}
$$

and

$$
\begin{aligned}
& \hat{p}_{2} / \rho=-\dot{\boldsymbol{v}}_{2} \nabla \phi^{0}+\dot{\boldsymbol{v}}_{1}\left(\nabla \nabla \phi^{0}\right) \boldsymbol{v}_{1}+\left(\boldsymbol{a} \times \boldsymbol{v}_{1}\right) \nabla \phi^{0} \\
& -\nabla \dot{\phi}^{1} \boldsymbol{v}_{1}-g \boldsymbol{v}_{2 z}-\left(\nabla \phi^{1}-\nabla \phi^{0} \times \boldsymbol{a}\right)^{2} / 2 \\
& -\left(\nabla \phi^{0}-\boldsymbol{U}\right) \cdot\left[\boldsymbol{v}_{1} \nabla \nabla \phi^{0} \times \boldsymbol{a}+\left(\boldsymbol{v}_{1} \times \boldsymbol{a}\right) \nabla \nabla \phi^{0}\right. \\
& \left.+\boldsymbol{v}_{1} \nabla \nabla \phi^{1}-\boldsymbol{v}_{1}\left(\nabla \nabla \nabla \phi^{0}\right) \boldsymbol{v}_{1}\right]
\end{aligned}
$$

respectively. Symbol $\nabla \nabla$ in the expression $\nabla \nabla \phi^{0}$ denotes an outer product, producing a matrix when applied to a scalar. Symbol $\nabla \nabla \nabla$ in the expression $\nabla \nabla \nabla \phi^{0}$ also denotes an outer product, producing a tensor of third-order when applied to a scalar.

The three terms in parentheses $A, B$, and $C$ in Eq. (7) comprise two harmonically oscillating factors contributing to the second-order force and moments, denoted as $a=\operatorname{Re}\left(\hat{a} \mathrm{e}^{\mathrm{i} \omega_{e} t}\right)$ and $b=\operatorname{Re}\left(\hat{a} \mathrm{e}^{\mathrm{i} \omega_{e} t}\right)$. The product of factors $a$ and $b$ are written as follows:

$$
\begin{aligned}
& a b=\operatorname{Re}\left(\hat{a} \mathrm{e}^{\mathrm{i} \omega_{e} t}\right) \operatorname{Re}\left(\hat{b} \mathrm{e}^{\mathrm{i} \omega_{e} t}\right) \\
& =\operatorname{Re}\left[\hat{a} \mathrm{e}^{\mathrm{i} \omega_{e} t} \operatorname{Re}\left(\hat{b} \mathrm{e}^{\mathrm{i} \omega_{e} t}\right)\right] \\
& =\operatorname{Re}\left[\hat{a} \mathrm{e}^{\mathrm{i} \omega_{e} t} \frac{1}{2} \operatorname{Re}\left(\hat{b} \mathrm{e}^{\mathrm{i} \omega_{e} t}+\left(\hat{b}^{*} \mathrm{e}^{-\mathrm{i} \omega_{e} t}\right)\right]\right. \\
& =\frac{1}{2} \operatorname{Re}\left(\hat{a} \hat{b} \mathrm{e}^{2 \mathrm{i} \omega_{e} t}+\hat{a} \hat{b}^{*}\right)
\end{aligned}
$$

where the upper index $*$ designates the complex conjugate. The first term oscillates harmonically at frequency $2 \omega_{e}$; its time average is zero. Therefore, the time average of $a b$ is as follows:

$\overline{a b}=\frac{1}{2} \operatorname{Re}\left(\hat{\mathrm{a}} \hat{b}^{*}\right)$

This formula is used to evaluate the time-average of a product of two first-order quantities. The time averages of terms $A$ and $B$ in Eq. (7) are thus evaluated as follows:

$\bar{A}=\frac{1}{2} \operatorname{Re}\left(\hat{\boldsymbol{\alpha}} \times \hat{p}_{1}^{*} \boldsymbol{f}\right), \bar{B}=\operatorname{Re}\left[\hat{\boldsymbol{\alpha}} \times\left(\hat{\boldsymbol{\alpha}}^{*} \times p_{0} \boldsymbol{f}\right)\right]$

To determine the time average of $\underline{p}_{2}$ at hull-fixed points in the term $C$ in Eq. (7), terms containing third-order space derivatives of steady potential $\phi^{0}$ are neglected, which yields the following result:

$\bar{C}=\frac{\rho f_{0}}{2} \operatorname{Re}\left\{\mathrm{i} \omega_{e}\left(\hat{\boldsymbol{\alpha}} \times \hat{\boldsymbol{v}}_{1}^{*}\right) \nabla \phi^{0}-\mathrm{i} \omega_{e} \nabla \hat{\phi} \hat{\boldsymbol{v}}_{1}^{*}\right\}$

$+\frac{1}{2}[0,0,-g]^{\mathrm{T}}\left[\hat{\boldsymbol{\alpha}} \times\left(\hat{\boldsymbol{\alpha}}^{*} \times \underline{\boldsymbol{x}}\right)\right]$

$-\frac{1}{2}\left|\nabla \hat{\phi}-\nabla \phi^{0} \times \hat{\boldsymbol{\alpha}}\right|^{2}$

$-\left(\nabla \phi^{0}-\boldsymbol{U}\right)\left[\hat{\boldsymbol{v}}_{\mathbf{1}} \nabla \nabla \hat{\phi}^{0} \times \hat{\boldsymbol{\alpha}}^{*}\right.$

$\left.\left.-\left(\hat{\boldsymbol{v}}_{\mathbf{1}} \times \hat{\boldsymbol{\alpha}}^{*}\right) \nabla \nabla \phi^{0}+\boldsymbol{v}_{1} \nabla \nabla \hat{\boldsymbol{\phi}}^{*}\right]\right\}$

The time-averaged value of the remaining force contribution $\mathrm{F}_{B}$ caused by the varying hull submergence is as follows:

$\overline{\boldsymbol{F}_{B}}=\sum_{\text {WL panels }} \frac{\left|\hat{p}_{w}\right|^{2}}{4 \rho g} \frac{\Delta_{s}\left(\underline{\boldsymbol{f}} \times \Delta_{s}\right)}{\left(\underline{\boldsymbol{f}} \times \Delta_{s}\right)_{3}}$

where $\hat{p}_{w}$ is the pressure oscillation amplitude on the time-averaged waterline and $\hat{p}_{w} /(\rho g)$ is the linearized vertical relative motion between the water surface and hull, including swell-up. Waterline (WL) panels are panels on the hull surface with two of their three corners located on the waterline, $\Delta_{S}$ is the vector between these corners, and index 3 designates the vertical component. Second-order moments are calculated in a similar way. 


\subsection{Calm Water Resistances}

Hughes (1954) proposed that total resistance $R_{T}$ can be described as the sum of wave resistance $R_{W}$ and frictional resistance $R_{F}$, formulated as follows:

$R_{T}=R_{W}+(1+k) R_{F}$

where $k$ is the form factor, which is generally calculated based on experimental data. It can be also estimated using for instance RANSE-CFD code with double-body flow at the model scale. The double body flow method dictated that the flow around the underwater body is symmetrical without free surface. In this situation, the form factor is expressed as $1+k=C_{V} / C_{F}, C_{V}$ is the viscous pressure coefficient, which was obtained from the simulation results from Starccm+, and $C_{F}$ could be obtained by Eq. (20). Detail calculation process can be found in the research of Dogrul et al. (2020). With this method, we obtain the form factors for DTC, KCS, and S-175, which are 0.094, 0.155, and 0.129 , respectively.

Wave resistance $R_{w}$ was calculated directly using code GL Rankine. To determine the total resistance, the tangential contribution due to viscosity, i.e., the frictional resistance $R_{F}$, was also needed. It was estimated as follows:

$R_{w}=0.5 \rho V^{2} S C_{F}$

for a water density of $\rho=998.8 \mathrm{~kg} / \mathrm{m}^{3}$ and for ship speed, $V$, where $S$ is the wetted area of the hull. The normalized resistance coefficient $C_{F}$, according to the ITTC (1957), was expressed as follows:

$C_{F}=\frac{0.075}{\left(\log _{10}(R e)-2.0\right)^{2}}$

where $R e=V L / v$ is Reynolds number, $L$ is ship length between perpendiculars, and $v=1.09 \times 10^{-6} \mathrm{~m}^{2} / \mathrm{s}$ is kinematic viscosity of water.

\subsection{Wave Added Resistance}

A ship sailing in the sea encounters waves from different directions. The total resistance in waves $R_{T w}$ consists of calm water resistance $R_{c w}$ and wave added resistance $R_{a w}$. It was expressed as follows:

$R_{T w}=R_{c w}+R_{a w}$

Angle $\mu$ represented the wave heading angle as shown in Figure 9. In head waves, $\mu=180^{\circ}$; in beam waves from port, $\mu$ varies between $60^{\circ}$ and $120^{\circ}$. Here we only computed the added resistance in regular waves and the associated the heave and pitch motions in head waves.
Using the GL Rankine code, we obtained the Froude-Krylov force, the radiation and diffraction forces, the waterline force, and the time-averaged drift force. The time-averaged drift force represents the wave added resistance $R_{a w}$. An associated normalized wave drift force, here known as the wave added resistance coefficient $C_{a w}$, was expressed as follows:

$C_{a w}=\frac{R_{a w}}{\rho g \xi^{2} B^{2} / L}$

where $\rho, g$, and $\xi$ are density, gravitational acceleration, and wave amplitude, respectively, and $R_{a w}$ is the average value of added resistance obtained directly from numerical simulations. For comparison with experimental results, we presented the mean added resistance of this ship in waves by this added resistance coefficient.

The ship motions were normalized as follows:

$\ddot{\theta}=\frac{\theta_{a} L}{2 \pi \xi}$

$\ddot{z}=\frac{z_{a}}{\xi}$

where $\theta_{a}$ and $Z_{a}$ are, respectively, pitch and heave amplitude. Symbol ${ }^{*}$ identifies normalized values.

\subsection{Numerical Performance}

In the simulation solver GL Rankine, we used unstructured grids with triangular panels on the submerged body surface and block-structured grids with quadrilateral panels on the free surface. Due to the symmetric structure of ships, only half of the ships' bodies and free surfaces were discretized. The same grid was used on a body, both for the steady and seakeeping problems. Typically, about 2000 panels per half body were employed. According to Riesner et al. (2019), a medium size grid of about 2000 panels was sufficiently fine to obtain reliable resistance predictions. Therefore, we could just set up the panel number in

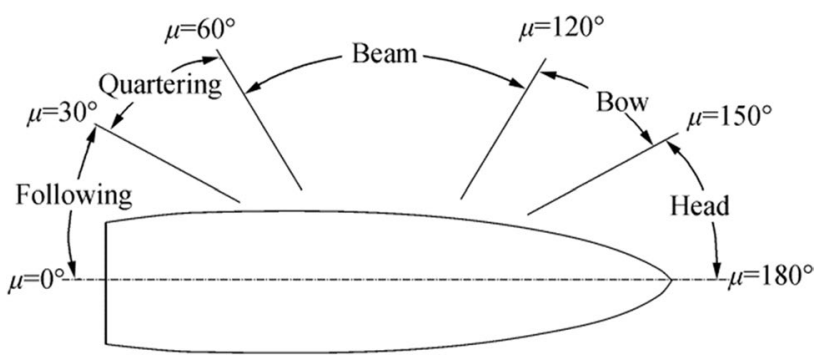

Figure 9 Definition of incident wave directions 
Figure 10 Comparison of panels of the model scaled ship DTC, KCS, and S-175 for GL Rankine computations

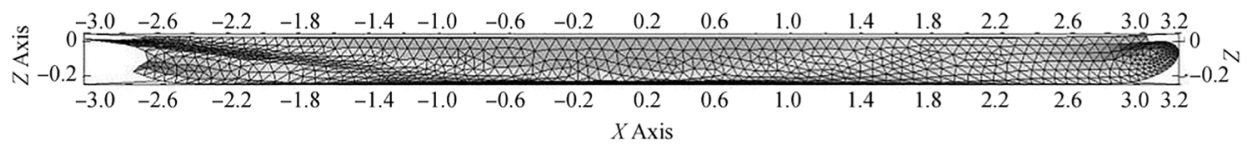

(a) DTC

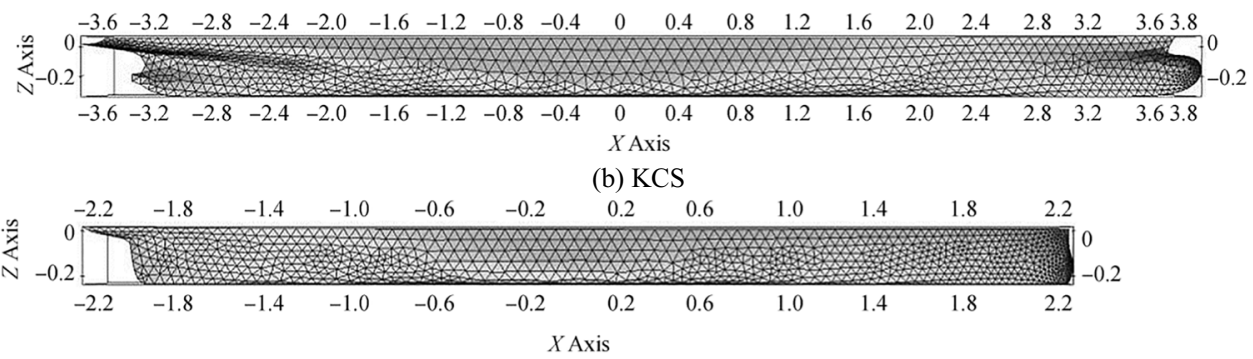

(c) S-175 the reliable range; the grid study process could be omitted. Here we performed our GL Rankine computations (at model scale) for the DTC, the KCS, and the S-175 on grids comprising 1723, 2178, and 2187 panels, respectively, as shown in Figure 10.

\section{Multi-Objective Optimization Problem}

We formulated our general optimization problem as follows:

Minimize : $f(\boldsymbol{x}), \boldsymbol{x} \in \mathfrak{R}^{n}$

$$
\begin{gathered}
\boldsymbol{x}_{l} \leq \boldsymbol{x} \leq \boldsymbol{x}_{u} \\
\text { Subject to : } \quad \boldsymbol{g}_{l} \leq \boldsymbol{g}(\boldsymbol{x}) \leq \boldsymbol{g}_{u}, \boldsymbol{h}(\boldsymbol{x})=\boldsymbol{h}_{t} \\
\boldsymbol{a}_{l} \leq \boldsymbol{A}_{l}(\boldsymbol{x}) \leq \boldsymbol{a}_{u}, \boldsymbol{A}_{e}(\boldsymbol{x})=\boldsymbol{a}_{t}
\end{gathered}
$$

In this formulation, $f(\boldsymbol{x})$ is the objective function, while $\boldsymbol{x}=\left[x_{1}, x_{2}, \cdots x_{n}\right]^{\mathrm{T}}$ is an $\mathrm{n}$-dimensional vector of real-valued design variables. Vectors $\boldsymbol{x}_{l}$ and $\boldsymbol{x}_{u}$ specify the lower and upper bounds of design variables, respectively. These bounds ensured that design variables changed within a reasonable range. The optimization goal was to minimize the objective function $f(\boldsymbol{x})$, while satisfying the constraints. These constraints were categorized as linear or nonlinear and as an inequality or an equality. The linear inequality constraints created a linear system $\mathrm{A}_{l}(\boldsymbol{x})$, where $\boldsymbol{A}_{l}$ is the coefficient matrix for the linear system and $\boldsymbol{a}_{l}$ and $\boldsymbol{a}_{u}$ are their lower and upper bounds, respectively. The linear equality constraints created a linear system $\boldsymbol{A}_{e}(\mathrm{x})$, where $\boldsymbol{A}_{e}$ is the coefficient matrix for the linear system and vectors $\boldsymbol{a}_{t}$ specify the target values. Vectors $\boldsymbol{g}(\mathrm{x})$ designate the nonlinear inequality constraints with lower and upper bounds $\boldsymbol{g}_{l}$ and $\boldsymbol{g}_{u}$, respectively. The nonlinear equality constraints $\boldsymbol{h}(\boldsymbol{x})$ had target values specified by $\boldsymbol{h}_{t}$. The constraints partitioned the parameter space into feasible and infeasible regions. A feasible design point had to satisfy all constraints.

\subsection{Objective Functions}

The objective functions to be minimized were the wave resistance $R_{W}$ and the frictional resistance $R_{F}$, both of which were described above.

\subsection{Constraints}

In the process of optimization, the selection of constraints was difficult. The entire hull form optimization was formulated to minimize total resistance under design conditions while satisfying the geometric constraints. The new hull form was subject to the following constraints:

- Change of total displacement was limited to one percent of the original displacement.

- Change of the longitudinal center of buoyancy was limited to one percent of the original longitudinal center of buoyancy.

- Change of the metacentric radius was limited to one percent of the original metacentric radius.

To obtain a reliable and flexible hull, technological constraints had to be considered as well. These constraints provided the upper and lower bounds of the design variables.

\subsection{Sensitivity Analysis}

A sensitivity analysis identified design parameters that had the greatest influence on response quantities. We employed framework CAESES and its optimization package DAKOTA to analyze the sensitivity of design variables and to identify those variables that significantly affected hull resistance. 
Table 3 Design variables, their definitions, and their lower and upper limits for the DTC and the KCS

\begin{tabular}{|c|c|c|c|c|c|c|c|c|}
\hline \multirow[t]{2}{*}{ Hull part } & \multirow[t]{2}{*}{ Design variables } & \multirow[t]{2}{*}{ Definition } & \multicolumn{3}{|l|}{ DTC } & \multicolumn{3}{|l|}{ KCS } \\
\hline & & & Initial value & Lower limit & Upper limit & Initial value & Lower limit & Upper \\
\hline \multirow[t]{7}{*}{ Bulbous bow } & BulbLength (m) & Length of bulbous bow & 9.642 & 9.000 & 12.00 & 6.501 & 5.050 & 8.950 \\
\hline & BulbTipZ (m) & $Z$ position of bulbous bow tip & 10.899 & 9.000 & 12.00 & 6.000 & 5.250 & 6.920 \\
\hline & yBeamStart (m) & $\begin{array}{l}Y \text { position of beam curve's start } \\
\text { point }\end{array}$ & 3.683 & 3.000 & 4.500 & 2.385 & 2.200 & 3.400 \\
\hline & xTop (m) & $\begin{array}{l}X \text { position of upper profile's start } \\
\text { point }\end{array}$ & 356.43 & 356 & 360 & 230.499 & 230 & 237 \\
\hline & FullnessBeam & $\begin{array}{l}\text { Fullness of beam curve of bulbous } \\
\text { bow }\end{array}$ & 1.025 & 0.900 & 1.200 & 1.155 & 1.030 & 1.30 \\
\hline & FullnessKeel & $\begin{array}{l}\text { Fullness of lower profile of bul- } \\
\text { bous bow }\end{array}$ & 0.978 & 0.855 & 1.050 & 0.925 & 0.85 & 1.1 \\
\hline & FullnessTop & $\begin{array}{l}\text { Fullness of upper profile of bul- } \\
\text { bous bow }\end{array}$ & 1.025 & 1.000 & 1.050 & 1.045 & 1.000 & 1.095 \\
\hline \multirow[t]{5}{*}{ Forebody } & $\operatorname{MidLift}(\mathrm{m})$ & Lift distance of middle body & 4.700 & 4.300 & 5.200 & 3.500 & 3.000 & 4.000 \\
\hline & DWLEntrTan $\left(^{\circ}\right)$ & Entrance angle of DWL & 165 & 161 & 170 & 177 & 170 & 177.1 \\
\hline & FullnessDWL & Fullness of DWL & 0.641 & 0.615 & 0.665 & 0.595 & 0.593 & 0.620 \\
\hline & FullnessFOBfore & Fullness of FOB from forebody & 0.445 & 0.420 & 0.490 & 0.405 & 0.350 & 0.500 \\
\hline & FullnessFOSfore & Fullness of FOS from forebody & 1.175 & 1.150 & 1.195 & 1.038 & 1.030 & 1.158 \\
\hline \multirow[t]{6}{*}{ Aftbody } & FullnessTransom & Fullness of transom curve & 0.955 & 0.945 & 1.000 & 0.975 & 0.950 & 0.990 \\
\hline & FullnessFOBaft & Fullness of FOB from aftbody & 0.325 & 0.300 & 0.332 & 0.485 & 0.415 & 0.533 \\
\hline & FullnessFOSaft & Fullness of FOS from aftbody & 1.185 & 1.150 & 1.200 & 1.105 & 1.000 & 1.140 \\
\hline & FullnessDiag1 & Fullness of diagonal 1 & 0.660 & 0.600 & 0.670 & 0.635 & 0.600 & 0.700 \\
\hline & FullnessDiag2 & Fullness of diagonal 2 & 0.551 & 0.500 & 0.552 & 0.568 & 0.500 & 0.585 \\
\hline & FullnessDiag3 & Fullness of diagonal 3 & 0.565 & 0.545 & 0.585 & 0.584 & 0.562 & 0.599 \\
\hline
\end{tabular}

Table 4 Design variables, their definitions, and their lower and upper limits for the S-175

\begin{tabular}{|c|c|c|c|c|c|}
\hline Hull part & Design variables & Definition & Initial value & Lower limit & Upper limit \\
\hline Stem & Stem_xtop (m) & $X$ position of stem tip & 176 & 175.5 & 176.5 \\
\hline \multirow[t]{7}{*}{ Shipbody } & TanDWL_out $\left(^{\circ}\right)$ & Out angle of DWL & 24.9 & 25 & 30 \\
\hline & TanDWL_entrance $\left(^{\circ}\right)$ & Entrance angle of DWL & 15 & 11 & 15.2 \\
\hline & FullnessFOS_fwd & Fullness of FOS from forebody & 0.635 & 0.5 & 0.67 \\
\hline & FullnessFOB_fwd01 & Fullness of FOB from forebody part one & 0.285 & 0.215 & 0.35 \\
\hline & FullnessFOB_fwd02 & Fullness of FOB from forebody part two & 1.215 & 1.18 & 1.3 \\
\hline & FullnessFOB_aft & Fullness of FOB from aftbody & 0.785 & 0.62 & 0.8 \\
\hline & FullnessDWL_fwd & Fullness of DWL from forebody & 0.585 & 0.578 & 0.595 \\
\hline Stern & Stern_change_point (m) & $X$ position of stern bending point & 4.375 & 2.5 & 5.5 \\
\hline
\end{tabular}

DAKOTA was useful for multi-objective optimizations, parameter predictions, uncertainty analyses, and sensitivity analyses.

Here, we exemplarily analyzed the sensitivity of the DTC's hull. Our executable file for this sensitivity analysis considered 100 samples. We analyzed the sensitivity of design variables for three parts of the hull, namely, the bulbous bow (14 parameters), the forebody (10 parameters), and the aftbody (13 parameters). Based on these results, we selected seven design parameters for the bulbous bow, five design parameters for the forebody, and six parameters for the aftbody. Due to the similarity of hull shapes of the DTC and the KCS, the selected design variables for the KCS were the same as those for the DTC.

Table 3 lists these design variables and their definitions. To meet ship stability requirements, the parametric model was only allowed to be changed within in a predefined range.

Table 3 includes also the lower and upper limits of the design variables for the DTC and the KCS. Unlike the DTC and the KCS, the S-175 does not have a bulbous bow. Therefore, the selected design variables for the S-175 differed from those for the DTC and the KCS. Table 4 lists the 

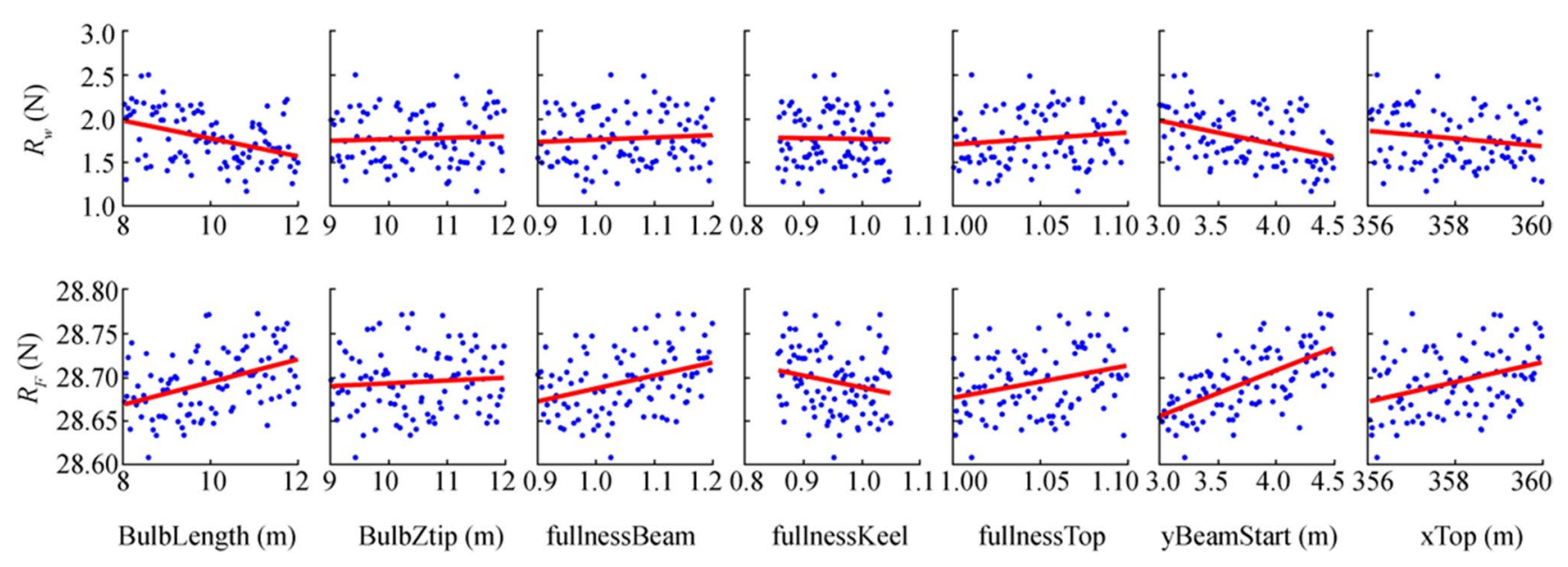

Figure 11 Sensitivity analysis of the seven design variables for the bulbous bow of the DTC (Feng et al. 2020b)

design values for the S-175, the limits of the selected design variables, and the associated lower and upper limits.

Taking the DTC as an example, Figures 11, 12 and 13 plot the influence of each design variable on ship resistance components $R_{W}$ and $R_{F}$ for the bulbous bow, the forebody, and the aftbody, respectively. It is worthy to mention that because we used potential solver to predict the resistance, that is, the pressure viscous resistance was not considered in this process. The changes of resistance on the aftbody, see Figure 13, were caused by the deformation of the stern. The individual graphs in these figures include straight (least squares) red lines drawn through the resulting values of $R_{W}$ and $R_{F}$ to demonstrate the influence of the changing parameter values.

\section{Optimization Algorithm}

In general, there is no unique optimum to design a multiobjective optimization problem. However, there is a set of points that represents the best compromise between different objectives, the so-called Pareto optimal values. Genetic algorithms are frequently used to perform multi-objective
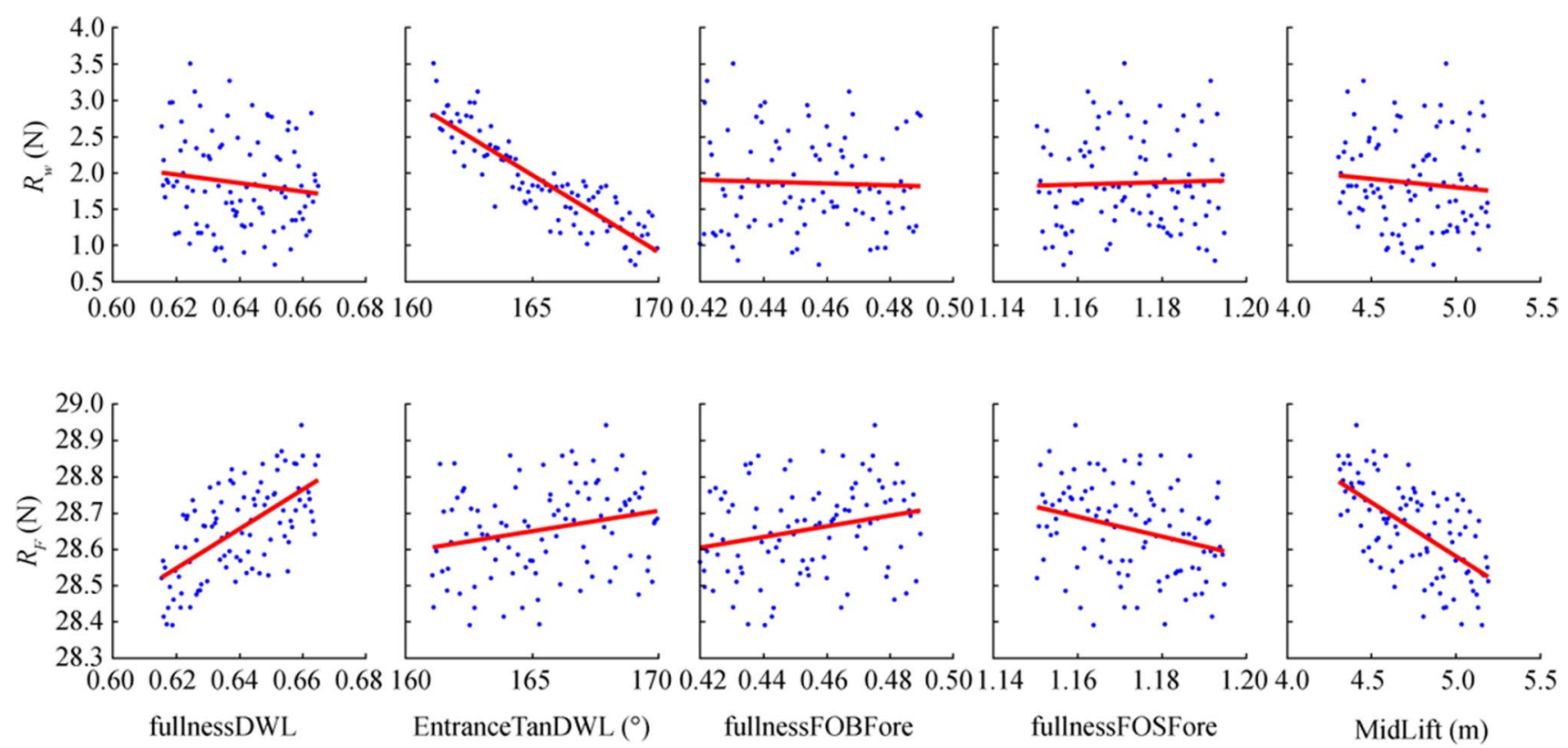

Figure 12 Sensitivity analysis of the five design variables for the forebody of the DTC (Feng et al. 2020b) 

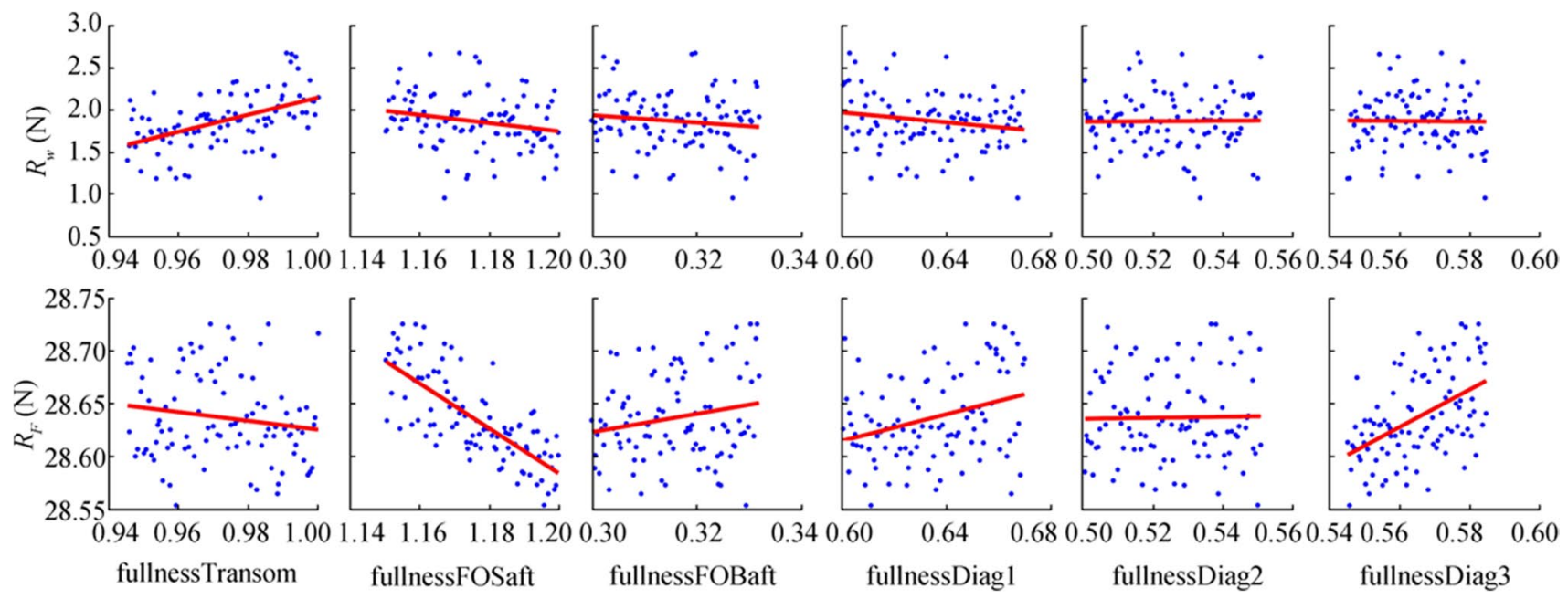

Figure 13 Sensitivity analysis of the six design variables for the aftbody of the DTC (Feng et al. 2020b)

optimizations. We applied the surrogate-based global optimization (SBGO) method for multi-objective optimizations in CAESES with DAKOTA.

Often, extensive calculations are necessary to evaluate the generated data. To reduce the computational effort of the optimization process, surrogate-based acceleration techniques can be used. Figure 14 presents the framework of the optimization process of Forrester and Keane (2009). This global method was originally designed for a multi-objective genetic algorithm (MOGA). In this method, the MOGA is conducted on an iteratively built-up surrogate model. For

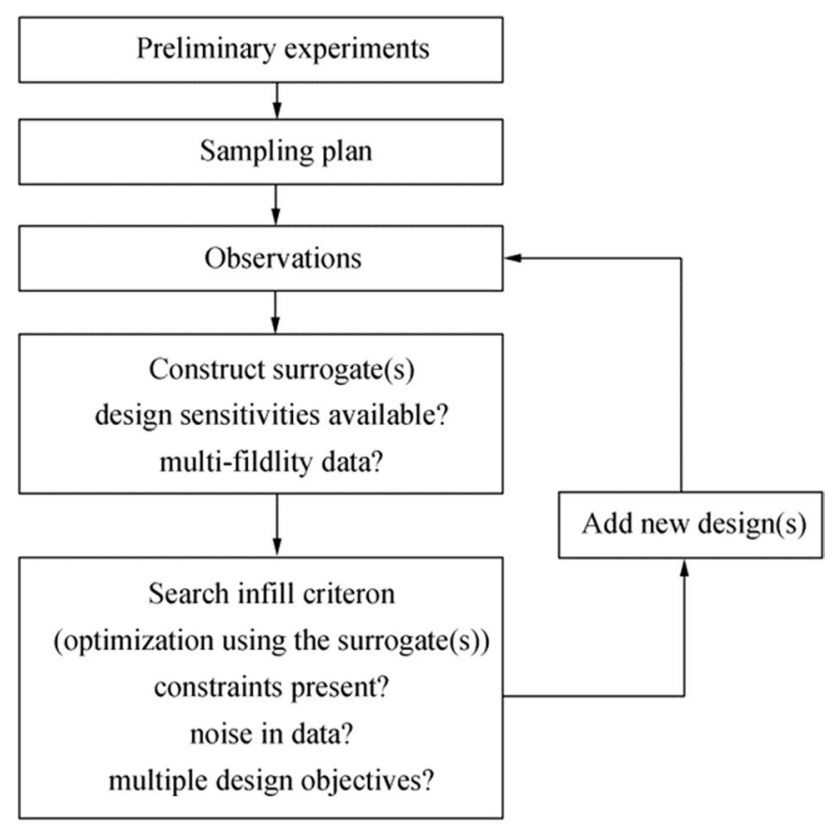

Figure 14 Framework of a surrogate-based optimization process of Forrester and Keane (2009)

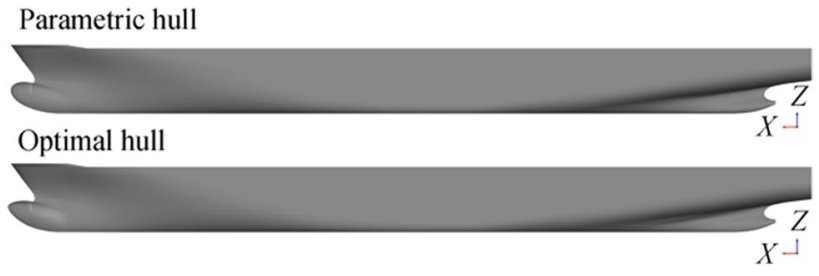

Figure 15 Comparison of the parametric hull and the optimal hull for the DTC at design speed

the initial model, data from the sensitivity analysis can be recycled as well. Since MOGA needs thousands of points to produce optimal solutions, surrogates can help by reducing the necessary model evaluations.

\section{Results and Discussion}

Due to their similar hull forms, simulation results and flow patterns were similar for the DTC and the KCS. For the DTC, we analyzed the influence of design variables

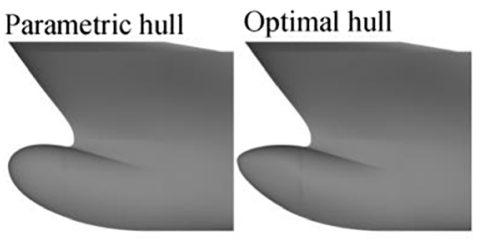

(a) Forebody

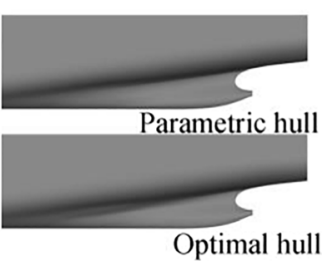

(b) Aftbody
Figure 16 Comparison of the parametric hull and optimal hull of the forebody and the aftbody for the DTC at design speed 

water resistances of the parametric hull (Par) and the optimal hull (Opt) and their
Table 5 Comparative calm differences (Diff) for the DTC

\begin{tabular}{|c|c|c|c|c|c|c|c|c|c|}
\hline \multirow[t]{2}{*}{$\overline{F r}$} & \multirow{2}{*}{$\begin{array}{l}R_{W}(\mathrm{~N}) \\
\text { Par }\end{array}$} & \multicolumn{4}{|c|}{$(1+k) R_{F}(\mathrm{~N})$} & \multicolumn{4}{|l|}{$R_{T}(\mathrm{~N})$} \\
\hline & & $\mathrm{Opt}$ & Diff $(\%)$ & Par & Opt & $\overline{\text { Diff }(\%)}$ & Par & Opt & Diff (\%) \\
\hline 0.174 & 0.916 & 0.301 & -67.15 & 20.761 & 20.751 & -0.05 & 21.677 & 21.052 & -2.88 \\
\hline 0.183 & 0.987 & 0.498 & -49.56 & 22.698 & 22.709 & 0.05 & 23.685 & 23.207 & -2.02 \\
\hline 0.192 & 1.170 & 0.650 & -44.47 & 24.776 & 24.709 & -0.27 & 25.946 & 25.359 & -2.26 \\
\hline 0.200 & 1.313 & 0.666 & -49.27 & 26.883 & 26.893 & 0.04 & 28.196 & 27.559 & -2.25 \\
\hline 0.209 & 1.782 & 0.761 & -57.28 & 29.087 & 29.108 & 0.07 & 30.869 & 29.869 & -3.24 \\
\hline 0.218 & 2.084 & 0.779 & -62.60 & 31.351 & 31.270 & -0.26 & 33.435 & 32.049 & -4.15 \\
\hline
\end{tabular}

on $R_{W}$ and $R_{F}$ and then listed the changes of resistance after the ship hull was optimized. After that, we calculated the dimensionless added resistance coefficient $C_{\text {aw }}$ of ship in head waves at $F r=0.139$ for DTC and at $F r=$ 0.260 for KCS. For the KCS, we compared wave profiles of the optimized hull with experimental data, and, instead of analyzing the resistance, we compared the simulated resistance coefficients with experimental results. These coefficients expressed the resistance values normalized against dynamic pressure times nominal wetted area. For the S-175, we simulated wave-induced the ship motions at $F r=0.250$ and compared these with experimental data.

\subsection{The DTC}

\subsubsection{Calm Water Resistance}

We demonstrated the use of a multi-objective optimization procedure to optimize the hull of the DTC for least resistance. We relied on fully parametric modeling to generate the hull in CAESES. The wave resistance and frictional resistance components were the objective functions. Figures 11, 12 and 13 graphically illustrate the influence of the selected design variables on the objective functions, i.e., on the two resistance components $R_{W}$ and $R_{F}$.

In Figure 11 we see that, for the bulbous bow, the influence of design variables Bulblength, yBeamStart, and xTop on $R_{W}$ and $R_{F}$ oppose each other. For the other four design variables, the influence of design parameters on $R_{W}$ and $R_{F}$ is the same. Specifically, the trend of variable Bulblength shows that the longer bulb decreased wave resistance and increased frictional resistance.

In Figure 12 we see that, for the forebody, the influence of design variables fullnessDWL and EntranceTanDWL on $R_{W}$ and $R_{F}$ oppose each other. For the other three design variables, the influence of design parameters on $R_{W}$ and $R_{F}$ is the same. Specifically, the trends of the variable fullness of the DWL indicate that the fuller forebody decreased wave resistance and increased frictional resistance.

In Figure 13 we see that, for the aftbody, the influence of design variables fullnessTransom, fullnessFOBaft, fullnessDiag1, and fullnessDiag3 on $R_{W}$ and $R_{F}$ oppose each other.

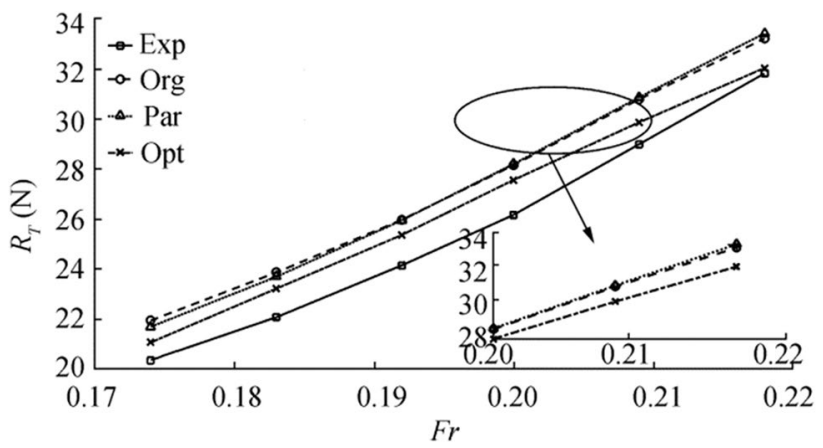

Figure 17 Comparison of total resistance for the original hull, the parametric hull, and the optimal hull of the DTC with experimental data

For the other two design variables, the influence of design parameters on $R_{W}$ and $R_{F}$ is the same. Specifically, the trends of variable fullnessTransom indicate that the fuller transom increased wave resistance and decreased frictional resistance.

Figure 15 compares the parametric hull and the optimal hull at design speed $(F r=0.218)$ of the DTC, and Figure 16 compares the DTC's parametric and optimal forebody and the aftbody. From these figures, we can see that the optimized hull has a longer and sharper bulbous bow than the parametric hull, and its keel region is slightly wider at the aftbody than the parametric hull.

After developing the parametric hull, we employed the validated potential flow code GL Rankine to compute wave resistance for the original hull, the parametric hull, and the optimal hull. For the six Froude numbers considered, Table 5 lists the resulting resistances for the parametric hull (Par) and the optimal hull (Opt) and the associated percentage reduction (Diff). At these Froude numbers, ranging from 0.174 and 0.218 , optimizing the parametric hull reduced wave resistance by at least $44.47 \%$ and by at most $67.15 \%$. At medium speeds, the decrease of wave resistance for the optimized hull was less than at low or high speeds.

Apart from the resulting wave and frictional resistances, Table 5 also lists the total resistance we obtained for the parametric hull and the optimal hull and their percentage difference. For the six Froude numbers considered, the optimization decreased total resistance for the parametric hull by 


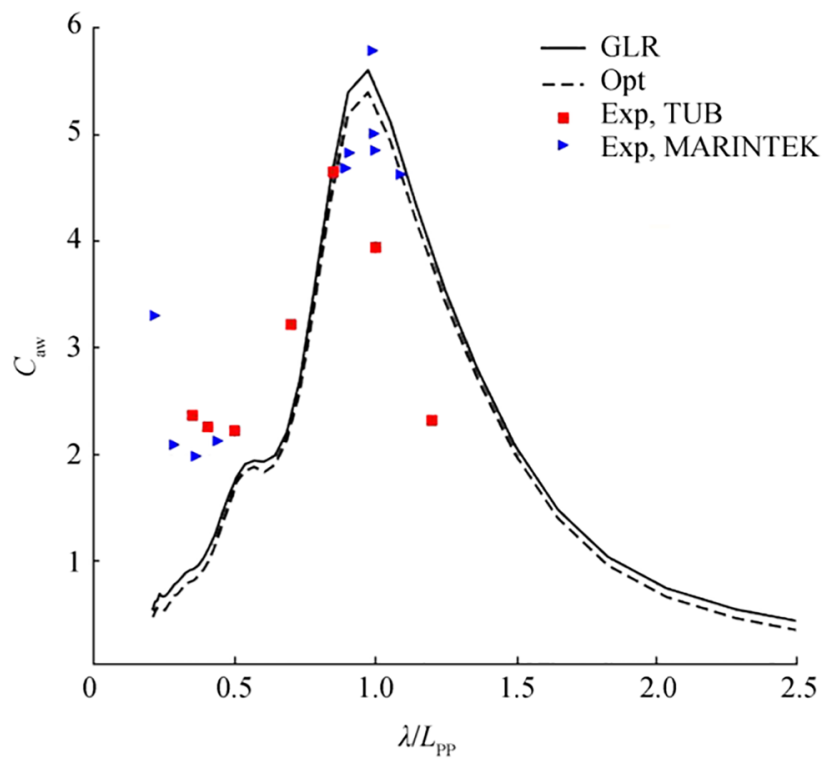

(a) $C_{\text {aw }}$

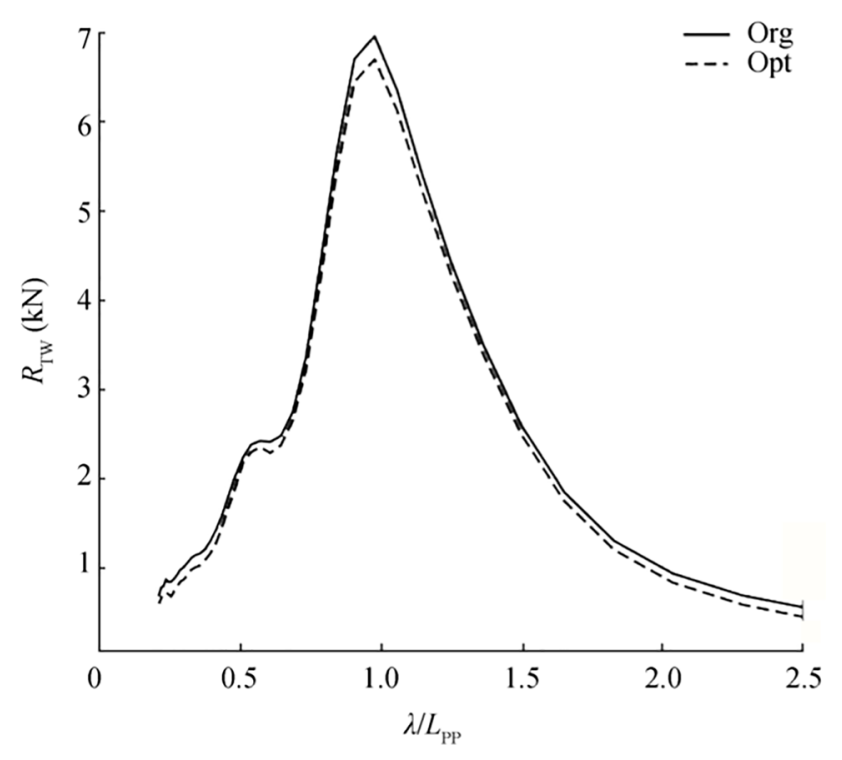

(b) $R_{\mathrm{Tw}}$

Figure 18 Wave added resistance coefficients and total resistance for the DTC in head waves at $F r=0.139$

at least $2.02 \%$ and by at most $4.15 \%$. These changes of total resistance show the same trend as the wave resistance. Thus, the successful reduction of wave resistance after optimization led to a decrease of total resistance for the optimized hull.

To compare these results, Figure 17 plots total resistance for the original hull, the parametric hull, and the optimal hull together with experimental data. Computed and experimental results differed by small amounts. The window inserted in this figure shows an enlarged view of the difference between
Table 6 Comparative resistance coefficients obtained from experiments (Exp), from GL Rankine simulations of the parametric hull (GLR), from GL Rankine simulations of the optimal hull (Opt), and their differences (Diff) for the DTC

\begin{tabular}{lllll}
\hline Fr & $\begin{array}{l}C_{T} \times 10^{3} \\
(\text { Exp })\end{array}$ & $\begin{array}{l}C_{T} \times 10^{3} \\
(\mathrm{GLR})\end{array}$ & $\begin{array}{l}C_{T} \times 10^{3} \\
(\mathrm{Opt})\end{array}$ & Diff (\%) \\
\hline 0.174 & 3.661 & 3.911 & 3.797 & -2.92 \\
0.183 & 3.605 & 3.880 & 3.797 & -2.14 \\
0.192 & 3.588 & 3.856 & 3.786 & -1.81 \\
0.200 & 3.602 & 3.847 & 3.754 & -2.43 \\
0.209 & 3.623 & 3.863 & 3.734 & -3.34 \\
0.218 & 3.670 & 3.859 & 3.711 & -3.83 \\
\hline
\end{tabular}

the three hulls and the experimental data. For the six Froude numbers considered, Table 5 lists the resulting total resistance for the parametric hull and the optimal hull and the associated percentage reduction. As seen, at these Froude numbers, ranging from 0.174 and 0.218 , the optimization affected frictional resistance only marginally.

We stated total resistance for the DTC via its resistance coefficient, expressed as the total resistance normalized by the dynamic pressure and the nominal wetted area according to the ITTC (2002b) formula as follows:

$C_{T}=\frac{R_{T}}{0.5 \rho S V^{2}}$

Table 6 lists the resistance coefficient for the DTC at six different Froude numbers obtained from experiments (Exp) (El Moctar et al., 2012), from GL Rankine simulations for the parametric hull (GLR), and from GL Rankine simulations for the optimal hull. The percentage differences (Diff) of these coefficients for the parametric and optimal hull are also listed in Table 6. From this table we can see that, at Froude numbers ranging between 0.174 and 0.218 , the total resistance coefficient of the optimal hull was reduced by at least $1.81 \%$ and by the most $3.83 \%$. Comparing with low and middle speeds, the reduction of total resistance coefficient increased at higher speeds.

Figure 20 plots the comparison results more intuitively. From this figure we can see that, the calculated results with GL Rankine code were bigger than the experimental data. But it shows the same tendency as the experimental results.

\subsubsection{Resistance in Regular Waves}

Simulations were performed for DTC advancing at $F r=$ 0.139 in regular head waves of different wavelengths with $\lambda / L_{\mathrm{pp}}$ ratios ranging between 0.45 and 2.5 . The wave frequency ranged between 2.2 and $5.6 \mathrm{rad} / \mathrm{s}$. Figure 18 plots wave added resistance coefficients and total resistances, respectively, against wave length to ship length ratio $\lambda / L_{\mathrm{pp}}$ 


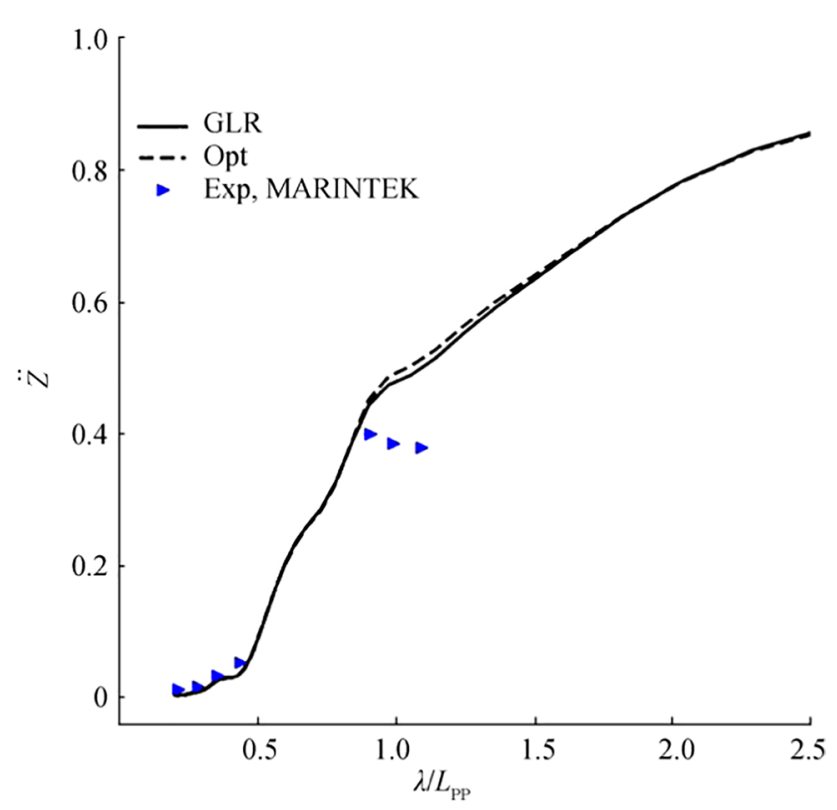

(a) Heave

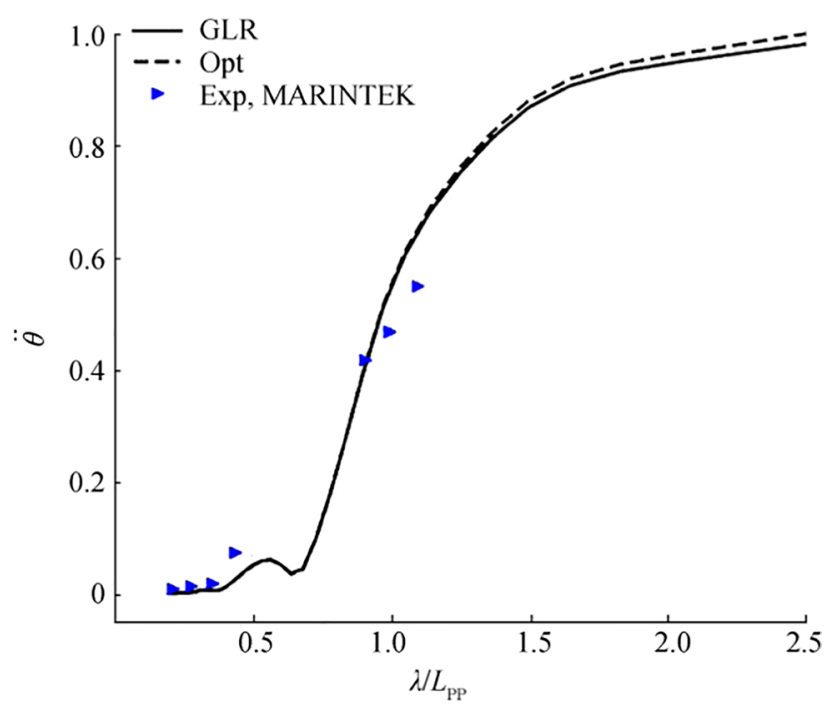

(b) Pitch

Figure 19 Heave and pitch responses for the DTC in head waves at $F r=0.139$

for the DTC in regular head waves at $F r=0.139$, and Figure 19 plots the associated heave and pitch responses against wave length to ship length ratio $\lambda / L_{\mathrm{pp}}$, also under these condition. Solid lines mark results for the parametric hull of the DTC obtained from code GL Rankine; dashed lines, the corresponding results for the optimal hull. Red squares represent experimental data provided by the Technical University Berlin (TUB). The DTC model was tested at the former Berlin Model Basin VWS at a scale of 1:89.11. Blue triangles represent experimental model tests of MARINTEK at a scale of 1:63.65 under deep water conditions.

As seen, added resistance coefficients based on GL Rankine computations are similar to added resistance coefficients

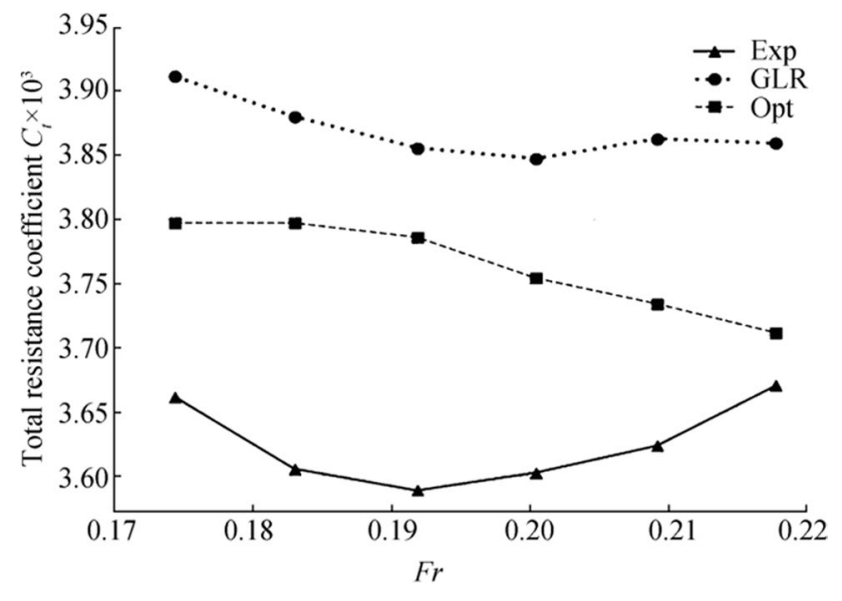

Figure 20 Comparative total resistance coefficients for the DTC

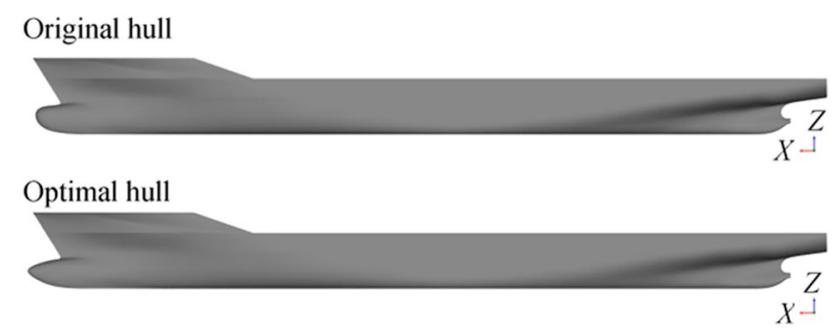

Figure 21 Comparison of the parametric hull and the optimal hull for the KCS at design speed

based on experimental measurements. For the optimal hull, wave added resistance coefficients are slightly reduced at $\lambda / L_{\mathrm{pp}}$ of about 1.0. The trends of total resistance of the original hull and optimal hull of the DTC are similar to the trends of wave added resistance coefficient. Numerical results of heave and pitch responses are almost identical when $\lambda / L_{\mathrm{pp}}<0.5$. At $\lambda / L_{\mathrm{pp}}$ of about 1.0 , numerically predicted heave response exceeds experimental measurements, while numerically predicted pitch response is only slightly higher than the experimental measurements. After the optimization

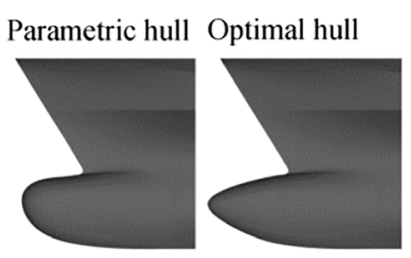

(a) Forebody

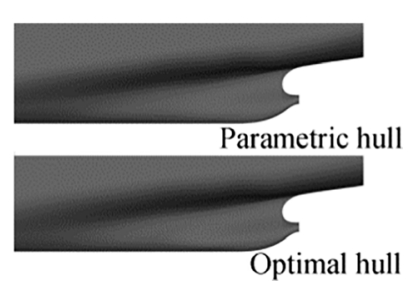

(b) Aftbody
Figure 22 Comparison of the parametric hull and the optimal hull of the forebody and the aftbody for the KCS at design speed 
Table 7 Comparative calm water resistances of the parametric hull (Par) and the optimal hull (Opt) and their differences (Diff) for the KCS

\begin{tabular}{|c|c|c|c|c|c|c|c|c|c|}
\hline \multirow[t]{2}{*}{$F r$} & \multicolumn{3}{|l|}{$R_{W}(\mathrm{~N})$} & \multicolumn{3}{|c|}{$(1+k) R_{F}(\mathrm{~N})$} & \multicolumn{3}{|l|}{$R_{T}(\mathrm{~N})$} \\
\hline & Par & Opt & Diff & Par & Opt & Diff & Par & Opt & Diff \\
\hline 0.108 & 0.359 & 0.006 & $-98.29 \%$ & 16.251 & 16.164 & $-0.54 \%$ & 16.610 & 16.170 & $-2.65 \%$ \\
\hline 0.152 & 1.400 & 0.116 & $-91.75 \%$ & 30.097 & 29.894 & $-0.67 \%$ & 31.497 & 30.010 & $-4.72 \%$ \\
\hline 0.195 & 1.943 & 0.962 & $-50.51 \%$ & 47.769 & 47.372 & $-0.83 \%$ & 49.712 & 48.334 & $-2.77 \%$ \\
\hline 0.227 & 3.303 & 1.168 & $-64.63 \%$ & 63.666 & 63.607 & $-0.09 \%$ & 66.969 & 64.775 & $-3.28 \%$ \\
\hline 0.260 & 11.224 & 5.779 & $-48.52 \%$ & 81.780 & 80.791 & $-1.21 \%$ & 93.004 & 86.570 & $-6.92 \%$ \\
\hline 0.282 & 34.596 & 21.373 & $-38.22 \%$ & 95.140 & 94.343 & $-0.78 \%$ & 129.736 & 115.757 & $-10.78 \%$ \\
\hline
\end{tabular}

process, heave and pitch responses in head waves changed only marginally when $\lambda / L_{\mathrm{pp}}<1.0$.

During all model tests, the DTC model was equipped with segmented bilge keels and a single rudder. However, our numerical simulations of the DTC were performed for the model without a rudder. As the rudder's contribution to overall resistance consisted mainly of friction, we evaluated its frictional resistance $R_{f r}$ as follows:

$R_{f r}=R_{F} \frac{S_{r}}{S}$

where $S_{r}$ is the wetted surface of rudder. For the DTC, the rudder is totally underwater. Thus, its wetted surface represents its area. According to classification society rules (DNVGL 2015), the frictional resistance caused by the rudder is less than $0.4 \%$ of total resistance. Therefore, the influence of the rudder was small enough to be neglected.

\subsection{The KCS}

\subsubsection{Calm Water Resistance}

Due to similar hull shape of the DTC and the KCS, we chose the same design variables and objective functions for the $\mathrm{KCS}$, and their design variables had the same influence on wave resistance and frictional resistance as for the DTC. Hence, we omitted the process of selecting design variables for the KCS and described the optimal results directly. Figure 21 compares the parametric (original) hull and the optimal hull for the KCS at design speed $(F r=0.260)$, and Figure 22 compares the associated parametric and optimal forebody and the aftbody. These figures show that the optimal hull is longer and has a sharper bulbous bow than the original hull, while the aftbody is only slightly altered after optimization. Therefore, here too we concluded that a longer and sharper bulbous bow lowered the resistance of the KCS's hull.

We considered six Froude numbers ranging from 0.108 to 0.282 . Table 7 lists the comparative resistances for the parametric hull (Par) and the optimal hull (Opt) of the KCS. The optimization reduced wave resistance of the parametric hull at least by $38.22 \%$ and at most by $98.29 \%$. At low speeds, the decrease of wave resistance for the optimized hull was more than at medium or high speeds. From the frictional resistance results, we see that the frictional resistance only decreased at least by $0.09 \%$ and at most by $1.21 \%$. These results were similar to those we obtained for the DTC, i.e., the optimization affected frictional resistance only marginally. For total resistance, the optimization decreased for the parametric hull at least by $2.65 \%$ and at most by $10.78 \%$. These changes of total resistance also show the same trend as the wave resistance.

To validate our simulated results, we compared the GL Rankine computed wave profiles obtained for the parametric and the optimal hull with experimentally measured wave profiles. Figure 23 plots these profiles as normalized wave elevations, $z / L_{\mathrm{pp}}$, versus normalized horizontal distance from amidships, $x / L_{\mathrm{pp}}$, where solid lines identify computed results for the parametric hull; dotted lines, computed results for the optimal hull; and black dots, experimental results for the model tested hull. This figure depicts also two so-called wave cuts, located at $y / L_{\mathrm{pp}}=0.0741$ and at $y / L_{\mathrm{pp}}=0.1509$. These wave cuts are wave profiles as they appear on a vertical plane parallel the hull's center plane located some distance from its centerline. Although the wave profile along the hull was generally well predicted by the GL Rankine method, the first wave peak and the second wave trough are somewhat under predicted. Nevertheless, in general, the predicted results compared favorably to the experimental results. For the optimal hull, wave peaks are lower and wave troughs are higher, and the first wave peak is slightly over predicted. These results demonstrated that the predicted wave field compared favorably to the measurements. Especially at the bow, the agreement is excellent in terms of both wave elevation and shape of the diverging wave groups.

We validated our predictions not only of total resistance, but also of the ship's sinkage and its trim against experimental data. Table 8 lists the resistance coefficient for the KCS at six different Froude numbers obtained from experiments (Exp), from GL Rankine simulations for the parametric hull (GLR), and from GL Rankine simulations for the optimal hull. Also listed are the percentage differences (Diff) of these coefficients for the parametric and the optimal 


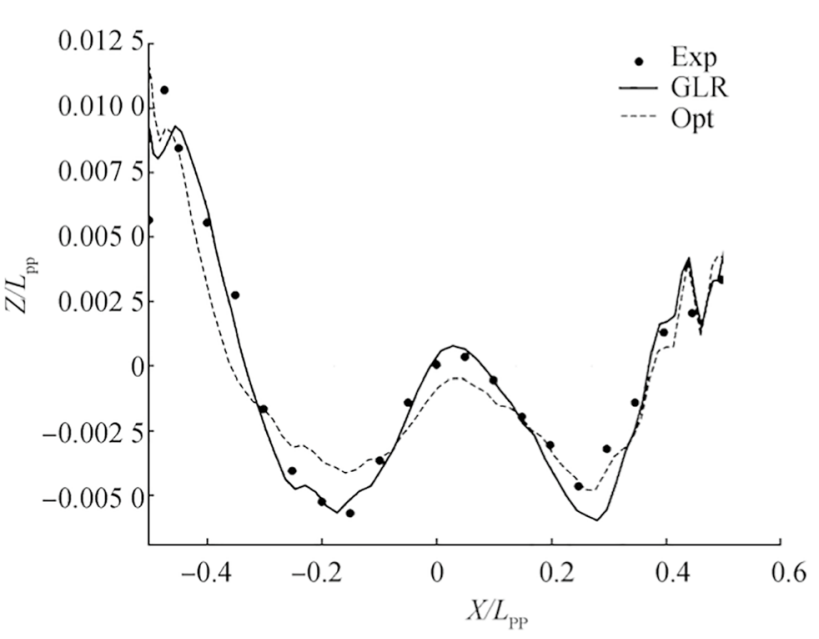

(a) On the hull

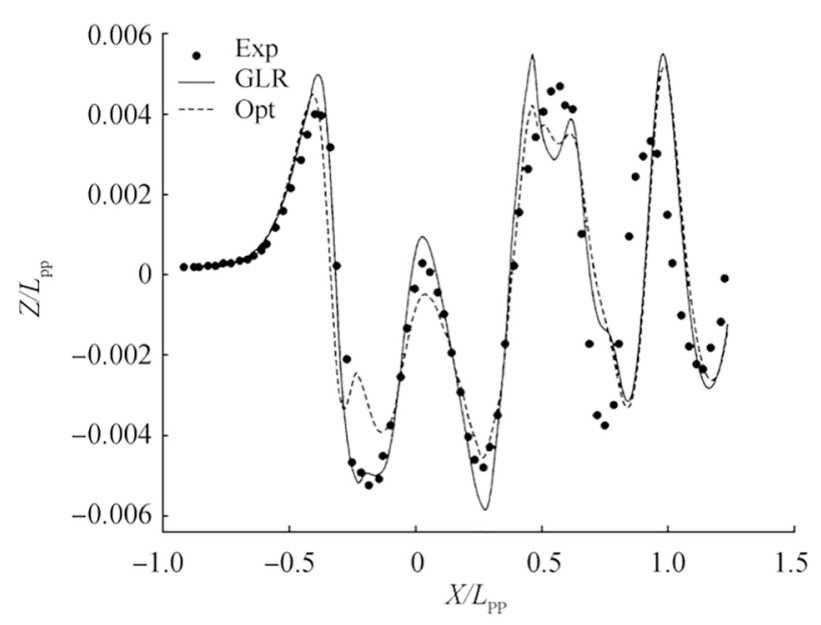

(b) On the wave cut at $y / L_{\mathrm{pp}}=0.0741$

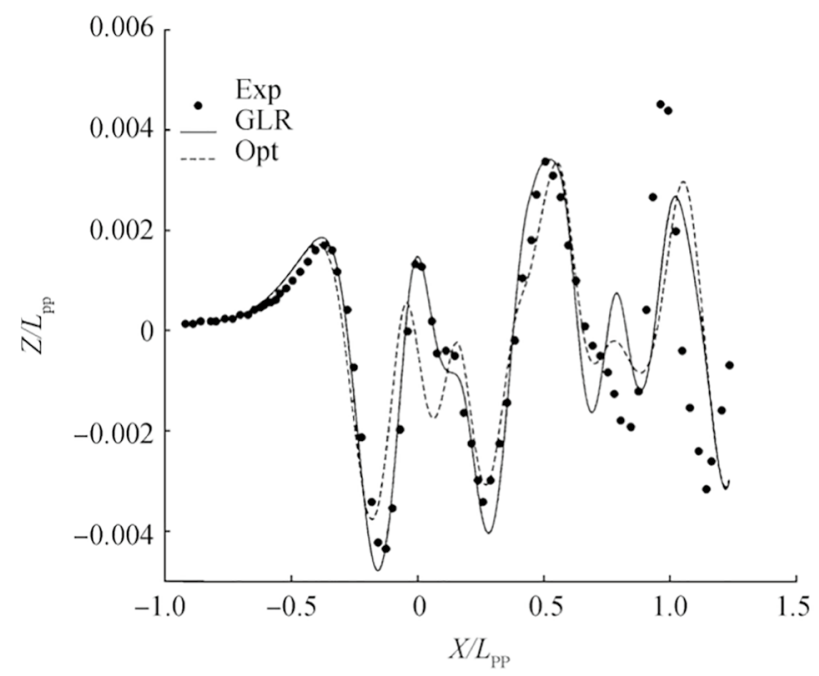

(c) On the wave cut at $y / L_{\mathrm{pp}}=0.1509$

Figure 23 Comparison of wave profiles on the hull, on the wave cut at $y / L_{\mathrm{pp}}=0.0741$, and on the wave cut at $y / L_{\mathrm{pp}}=0.1509$
Table 8 Comparative resistance coefficients obtained from experiments (Exp), from GL Rankine simulations of the parametric hull (GLR), from GL Rankine simulations of the optimal hull (Opt), and their differences (Diff) for the KCS

\begin{tabular}{lllll}
\hline Fr & $\begin{array}{l}C_{T} \times 10^{3} \\
(\mathrm{Exp})\end{array}$ & $\begin{array}{l}C_{T} \times 10^{3} \\
(\mathrm{GLR})\end{array}$ & $\begin{array}{l}C_{T} \times 10^{3} \\
(\mathrm{Opt})\end{array}$ & $\begin{array}{l}\text { Diff } \\
(\%)\end{array}$ \\
\hline 0.108 & 3.796 & 4.144 & 4.066 & -1.87 \\
0.152 & 3.641 & 4.008 & 3.835 & -4.31 \\
0.195 & 3.475 & 3.825 & 3.740 & -2.22 \\
0.227 & 3.467 & 3.784 & 3.657 & -3.36 \\
0.260 & 3.711 & 4.035 & 3.777 & -6.39 \\
0.282 & 4.501 & 4.789 & 4.273 & -10.77 \\
\hline
\end{tabular}

Table 9 Comparative values of sinkage obtained from experiments (Exp), from GL Rankine simulations of the parametric hull (GLR), from GL Rankine simulations of the optimal hull (Opt), and their differences (Diff) for the KCS

\begin{tabular}{lllll}
\hline$F r$ & $\begin{array}{l}\sigma \times 10^{2} \\
(\mathrm{~m})(\mathrm{Exp})\end{array}$ & $\begin{array}{l}\sigma \times 10^{2} \\
(\mathrm{~m})(\mathrm{GLR})\end{array}$ & $\begin{array}{l}\sigma \times 10^{2} \\
(\mathrm{~m})(\mathrm{Opt})\end{array}$ & Diff (\%) \\
\hline 0.108 & -0.090 & -0.191 & -0.179 & -6.23 \\
0.152 & -0.275 & -0.394 & -0.370 & -6.04 \\
0.195 & -0.599 & -0.697 & -0.667 & -4.30 \\
0.227 & -0.944 & -0.995 & -0.931 & -6.38 \\
0.260 & -1.394 & -1.363 & 1.302 & -4.44 \\
0.282 & -1.702 & -1.658 & -1.591 & -4.06 \\
\hline
\end{tabular}

Table 10 Comparative values of trim obtained from experiments (Exp), from GL Rankine simulations of the parametric hull (GLR), from GL Rankine simulations of the optimal hull (Opt), and their differences (Diff) for the KCS

\begin{tabular}{lllll}
\hline Fr & $\tau^{0}\left(^{\circ}\right)$ & $\tau^{0}\left(^{\circ}\right)$ & $\tau^{0}\left(^{\circ}\right)$ & Diff $(\%)$ \\
& $($ Exp $)$ & $(\mathrm{GLR})$ & $(\mathrm{Opt})$ & \\
\hline 0.108 & -0.017 & -0.022 & -0.018 & -17.09 \\
0.152 & -0.053 & -0.050 & -0.043 & -14.42 \\
0.195 & -0.097 & -0.092 & -0.077 & -15.38 \\
0.227 & -0.127 & -0.137 & -0.130 & -4.71 \\
0.260 & -0.169 & -0.189 & -0.180 & -4.88 \\
0.282 & -0.159 & -0.170 & -0.148 & -13.07 \\
\hline
\end{tabular}

hull. We see that, at Froude numbers ranging between 0.108 and 0.282 , the total resistance coefficient of the optimal hull was reduced by at least $1.87 \%$ and by at most $10.77 \%$. At the ship's design speed $(F r=0.260)$, the decrease of total resistance for the optimized hull was more than at lower speeds. Generally, at higher speeds, the reduction of total resistance increased.

Table 9 and 10 list, respectively, comparative values of sinkage and trim. As seen, over the range of ship speeds considered, optimizing the hull led to a relatively large reduction of trim and only slight decrease of sinkage. Specifically, 


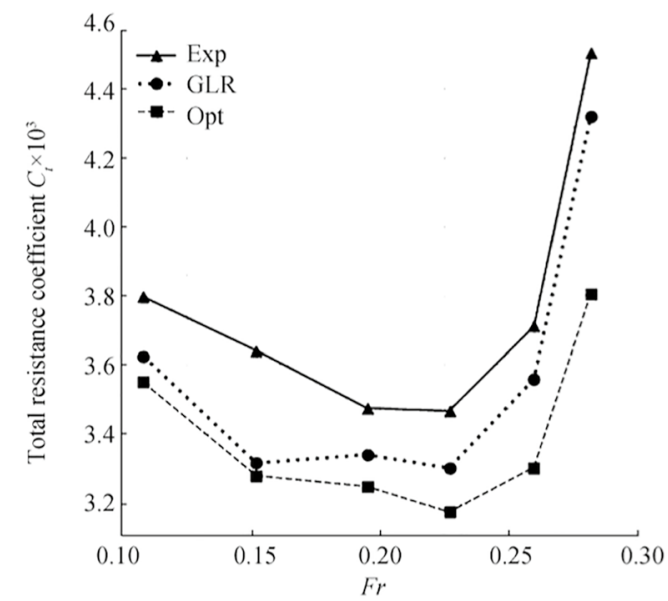

(a) Total resistance coefficients

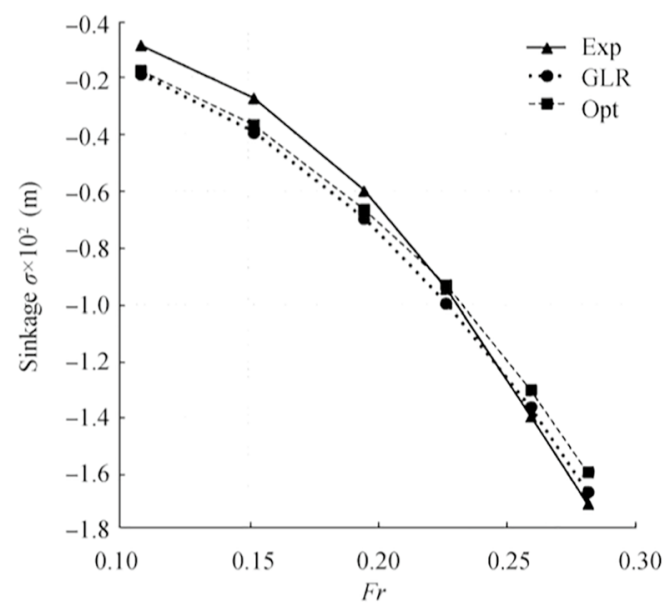

(b) Values of sinkage

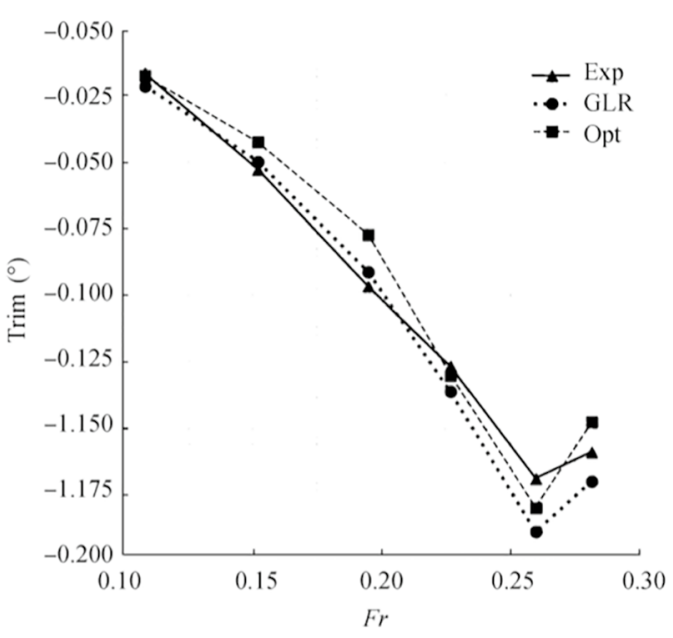

(c) Trim

Figure 24 Comparative total resistance coefficients and values of sinkage and trim for the KCS

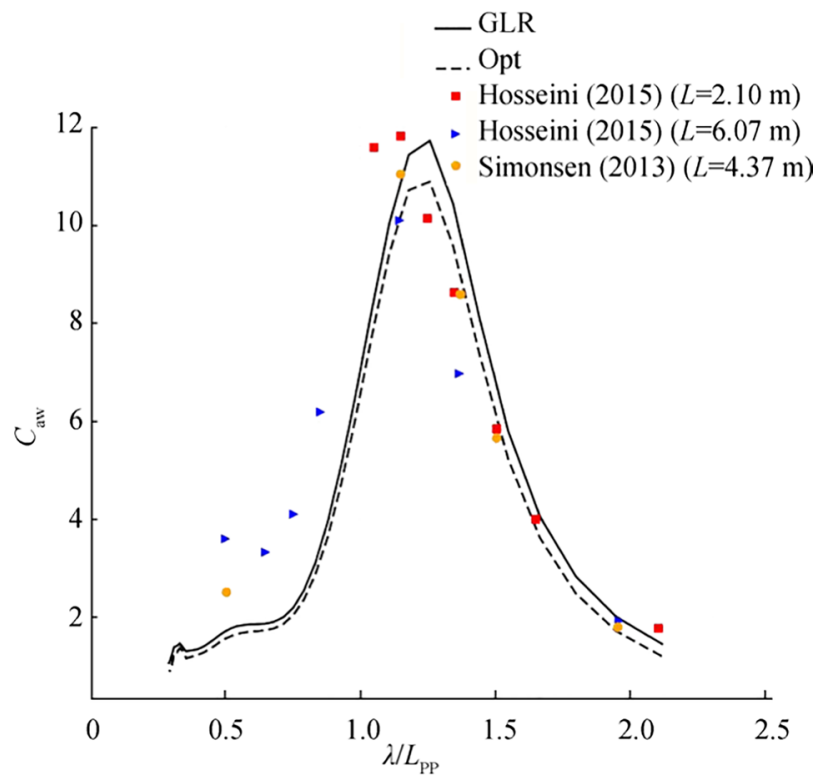

(a) $C_{\text {aw }}$

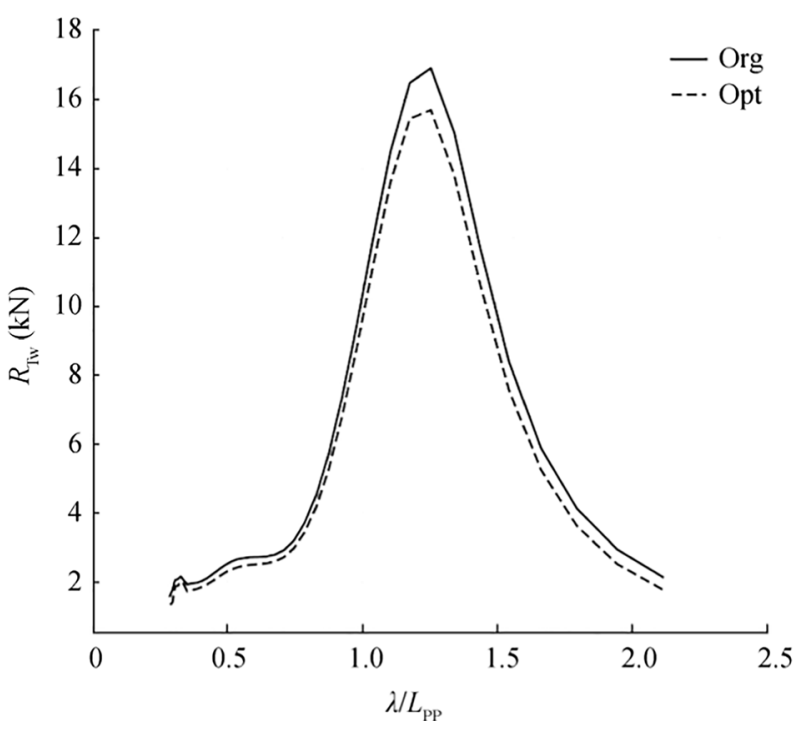

(b) $R_{\mathrm{Tw}}$

Figure 25 Wave added resistance coefficients and total resistance for the KCS in head waves at $\mathrm{Fr}=0.260$

optimizing the hull caused trim to decrease by at least by $4.71 \%$ and by at most $17.09 \%$ and sinkage to decrease by at least only $4.30 \%$ and by at most only $6.38 \%$. At lower and higher speeds, the reduction of trim was larger than at medium speeds.

Figure 24 summarizes these results graphically, showing plots of total resistance coefficients and values of sinkage and trim obtained from experiments (Exp), from GL Rankine simulations of the parametric hull (GLR), and from GL Rankine simulations of the optimal hull (Opt). 


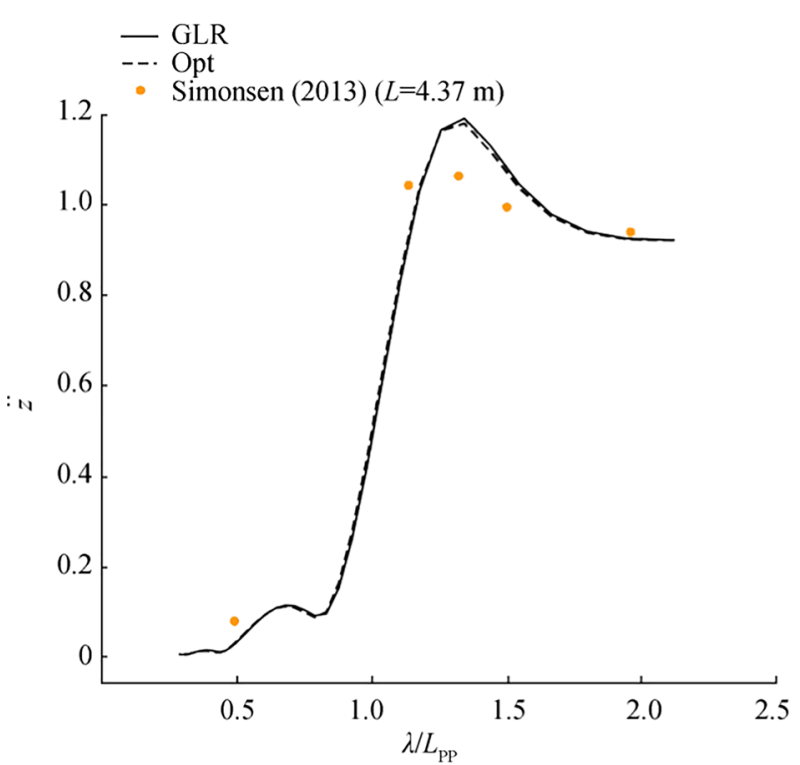

(a) Heave

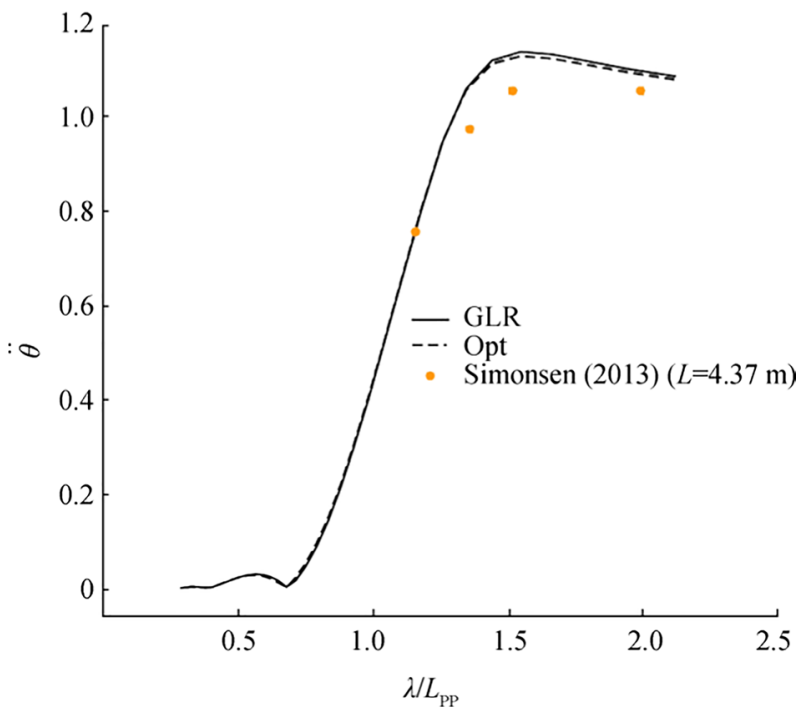

(b) Pitch

Figure 26 Heave and pitch responses for the KCS in head waves at $F r=0.260$

\subsubsection{Resistance in Regular Waves}

Simulations were performed for KCS advancing at $\mathrm{Fr}=$ 0.260 in regular head waves of different wavelengths with $\lambda / L_{\mathrm{pp}}$ ratios ranging between 0.3 and 2.1 . Wave frequencies ranged between 2.0 and $5.4 \mathrm{rad} / \mathrm{s}$. Figure 25 presents comparative wave added resistance coefficients and total resistances of the KCS in regular head waves of different encounter frequencies at $F r=0.260$. Figure 26 presents the heave and pitch responses for the KCS under the same condition. Similar to the results of DTC, solid lines mark results for the
Original hull

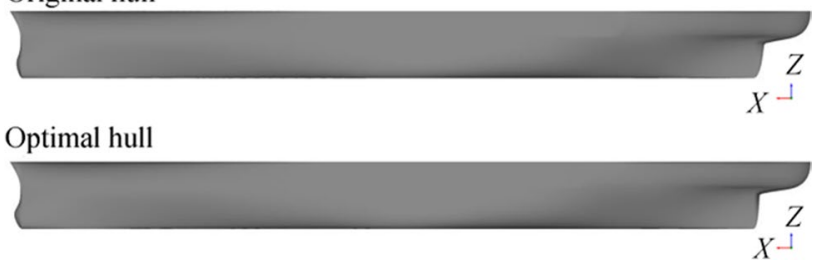

Figure 27 Comparison of the original hull and the optimal hull for the S-175 at $F r=0.250$

parametric hull of the KCS using GL Rankine code; dashed lines, results of the optimal hull. Red squares and blue triangles, respectively, represent experimental data of SadatHosseini et al. (2015) for the ship model with length $2.10 \mathrm{~m}$ and for the ship model with length $6.07 \mathrm{~m}$. The orange dot represents the experimental data of Simonsen et al. (2013) for the ship model with length $4.37 \mathrm{~m}$. As seen, the general trend of numerical results and experimental data of wave added resistance coefficient are consistent, but the numerical wave added resistance coefficients are slightly lower than the experimental ones when $\lambda / L_{\mathrm{pp}}<1.0$. The wave added resistance coefficients for the optimal hull are lower than those for the original hull when $\lambda / L_{\mathrm{pp}}>1.0$. Especially when $\lambda / L_{\mathrm{pp}}$ in the range 1.2 and 1.4 , this reduction is noticeable. Similar observations apply by comparing the total resistance of the original hull and optimal hull. The numerical results of heave and pitch responses are slightly higher than the experimental results when $1.0<\lambda / L_{\mathrm{pp}}<1.8$. After the optimization process, heave and pitch responses in head waves changed only marginally.

\subsection{The S-175}

\subsubsection{Calm Water Resistance}

The hull shape of the S-175 differed from the hull shapes of the DTC and the KCS. Figure 27 compares the original hull and the optimal hull for the S-175 at the Froude number of $\mathrm{Fr}$ $=0.250$, and Figure 28 compares the associated original and optimal stem and stern configurations. These figures show that

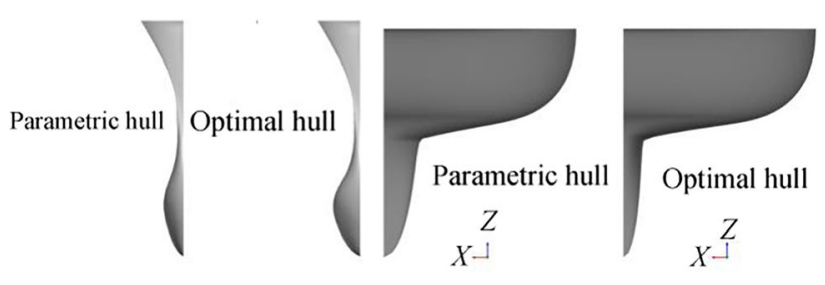

(a) Stem

(b) Stern

Figure 28 Comparison of stem and stern of the original and the optimal hull for the $\mathrm{S}-175$ at $\mathrm{Fr}=0.250$ 
Table 11 Comparative calm water resistances of the parametric hull (Par) and the optimal hull (Opt) and their differences (Diff) for the S-175 at $F r=0.250$

\begin{tabular}{|c|c|c|c|c|c|c|c|c|c|}
\hline \multirow[t]{2}{*}{$\mathrm{Fr}$} & \multicolumn{3}{|c|}{$R_{W}(\mathrm{~N})$} & \multicolumn{3}{|c|}{$(1+k) R_{F}(\mathrm{~N})$} & \multicolumn{3}{|l|}{$R_{T}(\mathrm{~N})$} \\
\hline & Par & Opt & Diff & Par & Opt & Diff & Par & Opt & Diff \\
\hline 0.250 & 5.253 & 2.882 & $-45.14 \%$ & 17.527 & 17.913 & $2.2 \%$ & 22.780 & 20.795 & $-8.71 \%$ \\
\hline
\end{tabular}

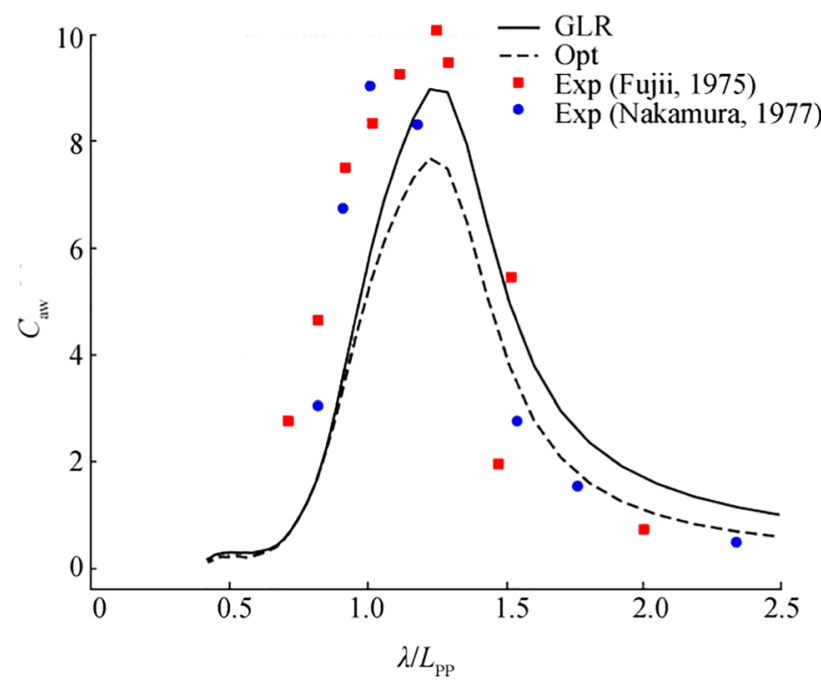

(a) Wave added resistance coefficient

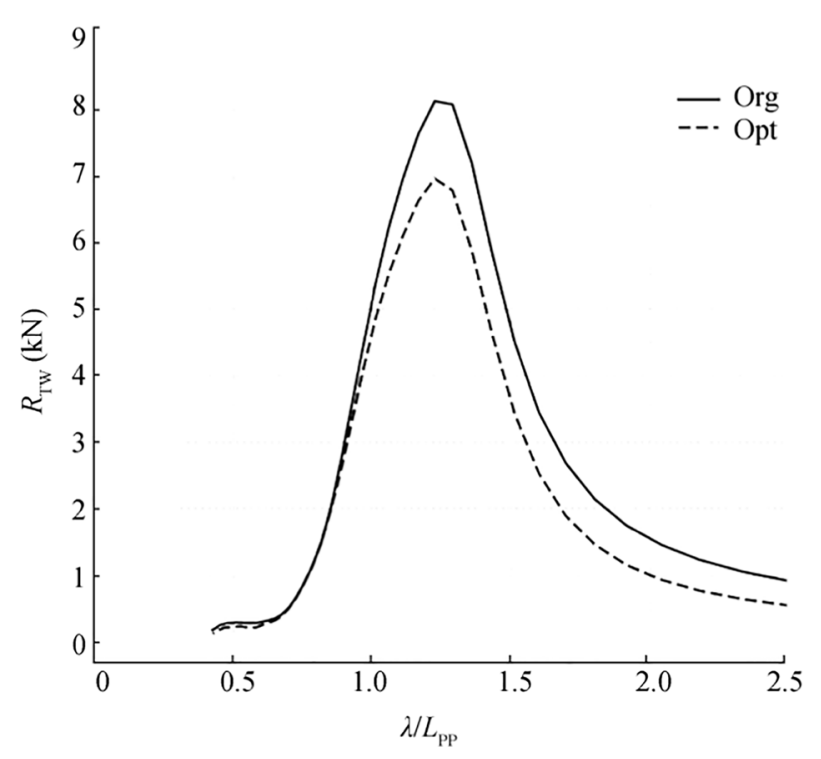

(b) Total resistance

Figure 29 Wave added resistance coefficients and total resistance for the S-175 in head waves at $F r=0.250$

the optimal hull has a longer stem and a thinner stern, which was also the case for the DTC and the KCS.

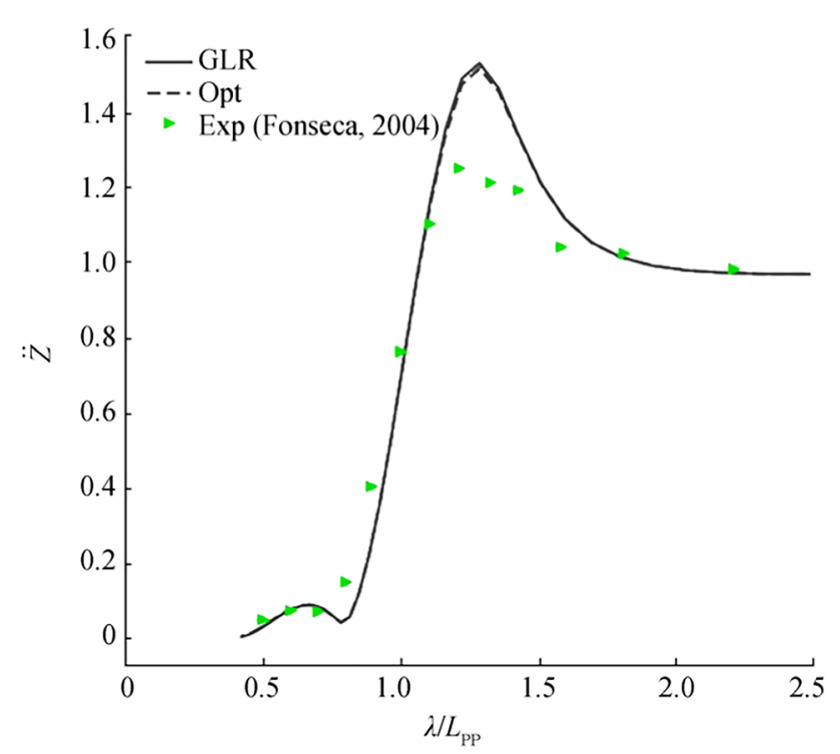

(a) Heave response

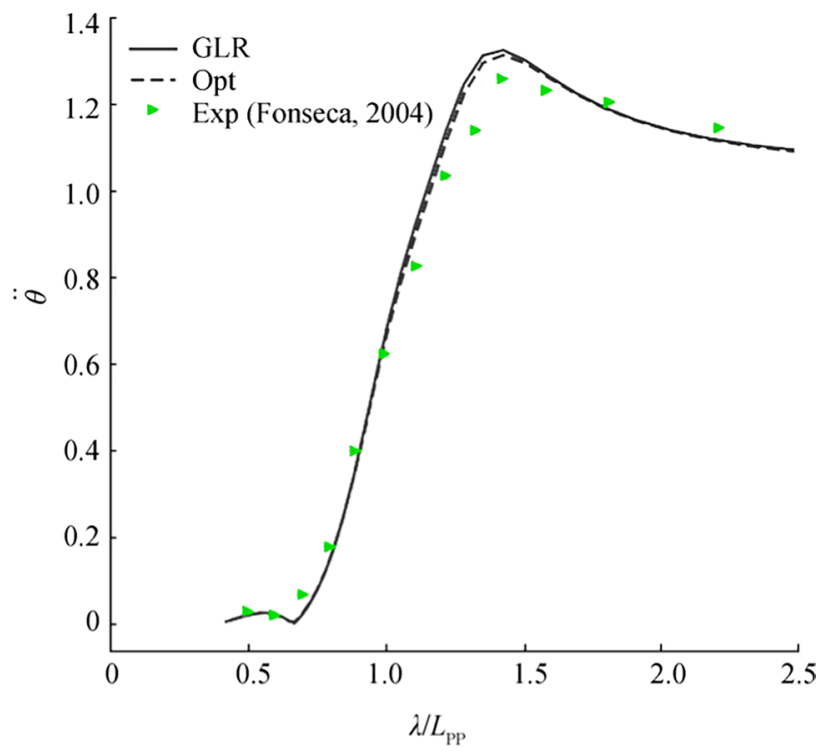

(b) Pitch response

Figure 30 Heave and pitch responses for the S-175 in head waves at $F r=0.250$

Table 11 lists comparative resistances for the parametric hull (Par) and the optimal hull (Opt) for the S-175 at 
the Froude number of $F r=0.250$ under calm water conditions. Symbol Diff represents for the difference values of resistance between parametric hull and optimal hull. Wave resistance, $R_{W}$, was reduced by $45.14 \%$ after the ship was optimized. Similar to the results of the DTC and the KCS, the frictional resistance, $R_{F}$, increased by $2.2 \%$. However, the total resistance, $R_{T}$, decreased by $8.71 \%$ after the optimization process.

\subsubsection{Resistance in Regular Waves}

Figure 29 shows the numerical results of wave added resistance coefficient and total resistance for different incident wave amplitudes for the ship S-175 at $F r=0.250$ in regular head waves. Figure 30 presents the heave and pitch responses under the same conditions. Solid lines identify computed results for the parametric hull; dashed lines, computed results for the optimal hull; red squares, experimental results of Fujii (1975); blue dots, experimental results of Nakamura and Naito (1977); green triangles, experimental results of Fonseca and Guedes Soares (2004). The left figure indicates that the results from the GL Rankine method agree reasonable well with the experimental results. The results of optimal hull for S-175 show a remarkable reduction on both wave added resistance coefficient and total resistance when $\lambda / L_{\mathrm{pp}}>1.0$. The left graph of Figure 30 shows that the results from the GL Rankine method overestimated the heave motions compared with experimental data when $\lambda / L_{\mathrm{pp}}$ is in the range between 1.2 and 1.6. Nevertheless, the computed values followed the same trend as the experimental data. The right graph of Figure 30 shows that the numerical results of pitch motions are close to the experimental data of pitch motions. The difference of heave and pitch motions between the original and the optimal hull for the S-175 was minimal. Therefore, the changing design variables for the ship hull hardly influenced heave and pitch motions in head waves.

\section{Conclusions}

Applying fully parametric modeling method, we created parametric hulls for three different sizes of containerships. Due to high similarity, the parametric hull for DTC can be applied on KCS after changing the corresponding parameters. As the KCS did not have a parallel midbody, a comparatively small value was assigned to its midbody to control its length. This reduced computational costs for generating a new parametric hull. Similarly, it can be also used to other containerships that are similar to DTC (i.e., a bulbous bow included). After the parametric hull was generated, with wave resistance and frictional resistance as the objective functions, the open source software DAKOTA was applied to develop the optimization procedure and to obtain the optimal hull shapes. To simulate the involved resistance, we employed the potential code GL Rankine to compute calm water resistance. The influence of ship sizes on the optimization process is compared and analyzed. Based on the optimization results, we predicted the wave added resistance and ship motions in head waves for the optimal hulls at certain Froude numbers (DTC, $F r=0.139$; KCS, $F r=0.260$; $\mathrm{S}-175, \mathrm{Fr}=0.250)$. The influence of the optimal hull on wave added resistance and ship motions were analyzed. The numerical results were compared with corresponding experimental data. All experimental measurements available for comparison with numerical results were obtained from model tests. Therefore, to avert scaling errors, all numerical investigations were conducted at model scale. The scale ratios for DTC, KCS, and S-175 were $1 / 59.407,1 / 31.599$, and $1 / 40$, respectively.

The optimizations of ship hulls under calm water conditions led to several conclusions. First, for the two larger containerships (with a bulbous bow), a longer sharper bulbous bow and a wider keel at the aftbody reduced wave resistance and, for the smaller containership (without a bulbous bow), a longer stem and a thinner stern reduced wave resistance. Second, at lower speeds, wave resistance for the optimized hulls was decreased by a larger amount than at medium and higher speeds. Third, at the considered range of Froude numbers, the optimization affected frictional resistance only marginally. Forth, the decrease of total resistance in calm water showed the same trend as the decrease of wave resistance. Fifth, for the studied containerships in this paper, the size of containerships did not show obvious and regular influence on the optimization results.

The GL Rankine code was employed to perform linear seakeeping analyses for three ships in regular head waves. Heave and pitch responses and wave added resistances agreed reasonably well with experimental measurements. Numerical results of optimal hulls of the three different size containerships demonstrated that the optimal hulls reduced wave added resistance and total resistance, especially for the small containership. However, the optimization process only slightly affected ship motions in head waves.

Funding Open Access funding enabled and organized by Projekt DEAL. This study is partly supported by the University Postgraduate Program ([2013]3009) through the China Scholarship Council (CSC) [N201306250034].

Open Access This article is licensed under a Creative Commons Attribution 4.0 International License, which permits use, sharing, adaptation, distribution and reproduction in any medium or format, as long as you give appropriate credit to the original author(s) and the source, provide a link to the Creative Commons licence, and indicate if changes were made. The images or other third party material in this article are included in the article's Creative Commons licence, unless indicated otherwise in a credit line to the material. If material is not included in the article's Creative Commons licence and your intended use is not permitted by statutory regulation or exceeds the permitted use, you will need to obtain permission directly from the copyright holder. To view a copy of this licence, visit http://creativecommons.org/licenses/by/4.0/. 


\section{References}

Adams, Brian, Bohnhoff, William, Dalbey, Keith, Ebeida, Mohamed, Eddy, John, Eldred, Michael, Hooper, Russell, Hough, Patricia, $\mathrm{Hu}$, Kenneth, Jakeman, John, Khalil, Mohammad, Maupin, Kathryn, Monschke, Jason A., Ridgway, Elliott, Rushdi, Ahmad, Seidl, Daniel, Stephens, John, and Winokur, Justin. Dakota, A Multilevel Parallel Object-Oriented Framework for Design Optimization, Parameter Estimation, Uncertainty Quantification, and Sensitivity Analysis: Version 6.13 User's Manual. United States: N. p., 2020. https://doi.org/10.2172/1817318

Brizzolara S, Vernengo G, Pasquinucci C, Haries S (2015). Significance of parametric hull form definition on hydrodynamic performance optimization. A: MARINE VI: proceedings of the VI International Conference on Computational Methods in Marine Engineering. CIMNE, 2015, p. 254-265. Retrieved from http:// hdl.handle.net/2117/332280. Accessed 16 Dec 2021

Chen J, Yu C, Chen L (2019) Study of trim optimization based on design of experiments and RANS simulation. 11th International Workshop on Ship and Marine Hydrodynamics, Hamburg. https:// doi.org/10.15480/882.3357

DNVGL (2015) Rules for Classification of Ships. Part 3 Hull, Chapter 14 Rudders and Steering, 1-48. Edition October 2015, amended January 2017. https://rules.dnv.com/docs/pdf/DNV/ruship/2017-01/DNVGL-RU-SHIP-Pt3Ch14.pdf

Dogrul A, Song S, Demirel YK (2020) Scale effect on ship resistance components and form factor. Ocean Eng 209:107428. https://doi. org/10.1016/j.oceaneng.2020.107428

El Moctar O, Schigunov V, Zorn T (2012) Duisburg test case: Postpanamax container ship for benchmarking. Ship Technol Res 59(3):50-64. https://doi.org/10.1179/str.2012.59.3.004

El Moctar O, Sigmund S, Lay J, Schellin TE (2017) Numerical and experimental analysis of added resistance of ships in waves. $\mathbf{J}$ Offshore Mech Arctic Eng 139(1):011301. https://doi.org/10. $1115 / 1.4034205$

Feng Y, El Moctar O, Schellin TE (2020a) Hydrodynamic optimisation of a multi-purpose wind offshore supply vessel. Ship Technol Res 67(2):69-83. https://doi.org/10.1080/09377255. 2019.1602976

Feng Y, El Moctar O, Schellin TE (2020b) Hydrodynamic optimization of a containership. Int Conf Offshore Mech Arctic Eng 84331:V02BT02A017. https://doi.org/10.1115/OMAE2 020-18616

Fonseca N, Guedes Soares C (2004) Experimental investigation of the nonlinear effects on the vertical motions and loads of a containership in regular waves. J Ship Res 48(2):118-147. https://doi.org/ 10.5957/jsr.2004.48.2.148

Forrester AI, Keane AJ (2009) Recent advances in surrogate-based optimization. Prog Aerosp Sci 45(1-3):50-79. https://doi.org/10. 1016/j.paerosci.2008.11.001

Fujii H (1975) Experimental study on the resistance increase of a ship in regular oblique waves. Proceeding of the 14th ITTC, Ottawa, pp 351-360

Gaggero ST, Villa D, Viviani M (2015) The Kriso container ship (KCS) test case: an open source overview. In: VI International Conference on Computational Methods in Marine Engineering. MARINE, Rome, pp 735-749

Hachmann D (1991) Calculation of pressures on a ship's hull in waves. Ship Techonol Res 38:111-133

Harries S (1998). Parametric design and hydrodynamic optimization of ship hull forms. PhD thesis, Institut fur Schiffs-und Meerestechnik, Technische Universitat Berlin, Berlin.

Harries S, Abt C (1998) Parametric curve design applying fairness criteria. In: International workshop, Creating fair and shape-preserving curves and surfaces. Teubner Verlag, Stuttgart, pp 67-78
Heinrich S (2009) A 3-D Rankine source seakeeping method. Ship Technol Res 56(2):50-68. https://doi.org/10.1179/str.2009.56.2. 002

Heinrich S, Schigunov V, Schellin TE, El Moctar O (2012) Rankine source method for seakeeping predictions. Am Soc Mech Eng 44915:449-460. https://doi.org/10.1115/OMAE2012-83450

Heinrich S, Schigunov V, Schellin TE, El Moctar O (2014) A Rankine panel method for added resistance of ships in waves. J Offshore Mech Arctic Eng 136(3):031601. https://doi.org/10.1115/1.40268 47

Hughes G (1954) Friction and form resistance in turbulent flow and a proposed formulation for use in model and ship correlation. In: Institution of Naval Architects. RINA Transactions, London, pp 1954-1916

ISMT (2012) Retrieved from Institute of Ship Technology, Ocean Engineering Transport Systems, University Duisburg-Essen. http:// www.uni-due.de/ISMT/. Accessed 16 Dec 2021

ITTC (2002a) Report of the specialist Committee of Extreme Ship Motions and Capsizing. 23rd International Towing Tank Conference, Venice

ITTC (2002b). Testing and extrapolation methods, resistance test. ITTC-Recommanded Procedures and Guidelines, 7.5-02.02.01, 23rd ITTC.

Kim W, Van S, Kim D (2001) Measurement of flows around modern commercial ship models. Exp Fluids 31(5):567-578. https://doi. org/10.1007/s003480100332

Kim M, Hizir O, Turan O, Day S, Incecik A (2017) Estimation of added resistance and ship speed loss in a seaway. Ocean Eng 141:465476. https://doi.org/10.1016/j.oceaneng.2017.06.051

Kracht A (1978) Design of bulbous bows. SNAME Trans 86(1):197-217

Kracht A, Jacobsen A (1992) D-series systematic experiments with models of fast twin-screw displacement ships. Soc Naval Architects Mar Eng 100:199-222

Kume KI (2000) Measurements of surface pressure and local velocity field around a KCS model and uncertainty analysis. Proceedings, Gothenburg 2000 - Workshop on Numerical Ship Hydrodynamics, Gothenburg

Larsson L, Stern F, Betram V (2003) Benchmarking of computational fluid dynamics for ship flows: the Gothenburg 2000 Workshop. J Ship Res 47(1):63-81. https://doi.org/10.5957/jsr.2003.47.1.63

MOERI (2008). MOERI Container Ship (KCS). Retrieved from http:// www.simman2008.dk/KCS/container.html. Accessed 16 Dec 2021

Nakamura S, Naito S (1977) Propulsive performance of a container ship in waves. J Soc Naval Architects Jpn 15:24-48

Nowacki H (1977) Ship lines creation by computer-objectives, methods, and results. Symposium on Computer-Aided Hull Surface Definition. Retrieved from https://ci.nii.ac.jp/naid/10030565389/ en/. Accessed 16 Dec 2021.

Papanikolaou A, Liu S (2010) On the prediction of added resistance of ships in waves. William Froude Conf: Adv Theor Appl Hydrodyn-Past, Future. https://doi.org/10.1016/j.oceaneng.2010.12.007

Queipo NV, Haftka RT, Shyy W, Goel T, Vaidyanathan R, Tucker PK (2005) Surrogate-based analysis and optimization. Prog Aerosp Sci 41(1):1-28. https://doi.org/10.1016/j.paerosci.2005.02.001

Riesner M, El Moctar O (2018) A time domain boundary element method for wave added resistance of ships taking into account viscous effects. Ocean Eng 162:290-303. https://doi.org/10.1016/j. oceaneng.2018.05.010

Riesner M, El Moctar O, Schellin TE (2018) Design related speed loss and fuel consumption of ships in seaways. Progress in Maritime Technology and Engineering: Proceedings of the 4th International Conference on Maritime Technology and Engineering, Lisbon. https://doi.org/10.1201/9780429505294-18 
Riesner M, Chillcce G, El Moctar O (2019) Rankine source time domain method for nonlinear ship motions in steep oblique waves. Ships Offshore Struct 14(3):295-308. https://doi.org/10.1080/ 17445302.2018.1498568

Rotteveel E, van der Ploeg A, Hekkenberg R (2016) Optimization of ships in shallow water with viscous flow computa-tions and surrogate modeling. 13th International Symposium on Practical Design of Ships and Other Floating Structures, Copenhagen

Sadat-Hosseini H, Toxopeus S, Kim DH, Catiglione T, Sanada Y, Stocker M, Simonsen C, Otzen JF, Toda Y, Stern F (2015) Experiments and computations for KCS added resistance for variable heading. Procceding of the 5th World Maritime Technology Conference, Rhode Island

Scholcz TP, Veldhuis CH (2017) Multi-objective surrogate based hull-form optimization using high-fidelity RANS computations. MARINE, Barcelona, pp 231-242

Scholcz TP, Gornicz T, Veldhuis CH (2015) Multi-objective hull-form optimization using Kriging on noisy computer experiments. International Conference on Computational Methods in Marine Engineering, Rome, pp 1064-1077

Simonsen CD, Otzen JF, Joncquez S, Stern F (2013) EFD and CFD for KCS heaving and pitching in regular head waves.
J Mar Sci Technol 18(4):435-459. https://doi.org/10.1007/ s00773-013-0219-0

Somayajula A, Guha A, Falzarano J, Chun HH, Jung KH (2014) Added resistance and parametric roll prediction as a design criteria for energy efficient ships. Ocean Syst Eng 4(2):117-136. https://doi. org/10.12989/OSE.2014.4.2.117

Tun TY (2016). Ship hull optimization in calm water and moderate sea states. Master thesis, Rostock.

Van S (1997) Measurement of flows around a 3600TEU container ship model. In: Proceedings, Annual Autumn Meeting. SNAK, Seoul, pp 300-304

Van S (1998a) Flow measurement around a 300K VLCC model. Proceedings of the Annual Spring Meeting, Ulsan, pp 185-188

Van S (1998b) Experimental investigation of the flow characteristics around practical hull forms. Third Osaka Colloquium on Advanced CFD Applications to Ship Flow and Hull Form Design, Osaka

Zhang ZR (2010) Verification and validation for RANS simulation of KCS container ship without/with propeller. J Hydrodyn 22(1):889-896. https://doi.org/10.1016/S1001-6058(10)60055-8 